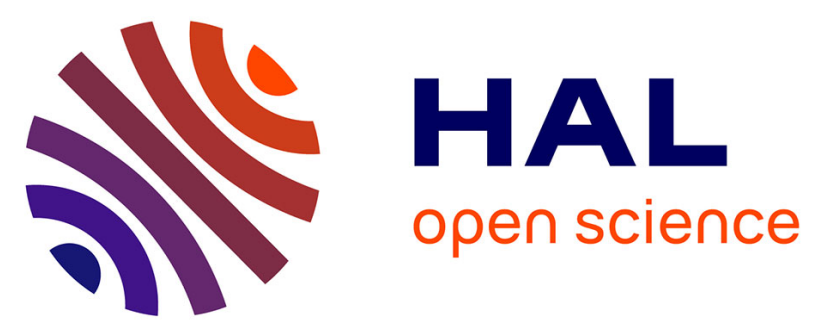

\title{
Observation of low-level wind reversals in the Gulf of Lion area and their impact on the water vapour variability
}

\author{
Paolo Di Girolamo, Cyrille Flamant, Marco Cacciani, Evelyne Richard, \\ Véronique Ducrocq, Donato Summa, Dario Stelitano, Nadia Fourrié, \\ Frédérique Saïd
}

\section{To cite this version:}

Paolo Di Girolamo, Cyrille Flamant, Marco Cacciani, Evelyne Richard, Véronique Ducrocq, et al.. Observation of low-level wind reversals in the Gulf of Lion area and their impact on the water vapour variability. Quarterly Journal of the Royal Meteorological Society, 2016, 142 (S1), pp.153172. 10.1002/qj.2767 . insu-01275554

\section{HAL Id: insu-01275554 https://hal-insu.archives-ouvertes.fr/insu-01275554}

Submitted on 18 Feb 2022

HAL is a multi-disciplinary open access archive for the deposit and dissemination of scientific research documents, whether they are published or not. The documents may come from teaching and research institutions in France or abroad, or from public or private research centers.
L'archive ouverte pluridisciplinaire HAL, est destinée au dépôt et à la diffusion de documents scientifiques de niveau recherche, publiés ou non, émanant des établissements d'enseignement et de recherche français ou étrangers, des laboratoires publics ou privés. 


\title{
Observation of low-level wind reversals in the Gulf of Lion area and their impact on the water vapour variability
}

\author{
P. Di Girolamo, ${ }^{\mathrm{a}}$ C. Flamant, ${ }^{\mathrm{b}}$ M. Cacciani, ${ }^{\mathrm{c}}$ E. Richard, ${ }^{\mathrm{d}}$ V. Ducrocq, ${ }^{\mathrm{e}}$ D. Summa, ${ }^{\mathrm{a}}$ D. Stelitano, ${ }^{\mathrm{a}}$ \\ N. Fourriée and F. Saïd ${ }^{\mathrm{d}}$ \\ ${ }^{a}$ Scuola di Ingegneria, Università degli Studi della Basilicata, Potenza, Italy \\ ${ }^{\mathrm{b}}$ LATMOS/IPSL, UPMC Univ. Paris 06 Sorbonne Universités, UVSQ, CNRS, Paris, France \\ 'Dipartimento di Fisica, Università di Roma 'Sapienza', Roma, Italy \\ ${ }^{\mathrm{d}}$ Laboratoire d'Aérologie, Université de Toulouse, CNRS, UPS, France \\ ${ }^{\mathrm{e}}$ CNRM, UMR 3589, Météo-France \& CNRS, Toulouse, France
}

Water vapour measurements from a ground-based Raman lidar and an airborne differential absorption lidar, complemented by high-resolution numerical simulations from two mesoscale models (AROME-WMED and Meso-NH), are considered to investigate three transition events from Mistral/Tramontane to southerly marine flow taking place in the Montpellier region (southern France) in the time frame September-October 2012, during the Hydrological Cycle in the Mediterranean Experiment Special Observation Period 1. Low-level wind reversals associated with these transitions are found to have a strong impact on water vapour transport, leading to a large variability of the water vapour vertical and horizontal distributions. Water vapour mixing ratio within the boundary layer is found to vary from typical values in the range $4-8 \mathrm{~g} \mathrm{~kg}^{-1}$ during the Mistral/Tramontane flows to values in the range $8-15 \mathrm{~g} \mathrm{~kg}^{-1}$ during the southerly marine flows. The increase/decrease in water vapour mixing ratio within the boundary layer may be abrupt and marked during these transition periods, with values increasing/decreasing by a factor of $2-4$ within $1 \mathrm{~h}$. The high spatial and temporal resolutions of the lidar data allow monitoring the time evolution of the water vapour field during these transitions from predominantly northerly Mistral/Tramontane flow to a predominantly southerly flow, permitting identification of the quite sharp separation between these flows, which is also satisfactorily well captured by the mesoscale models. Water vapour measurements from the ground-based lidar are complemented by particle backscatter measurements from the same system, which reveal the significant variability in the aerosol and cloud fields associated with these transition events.

Key Words: Raman lidar BASIL; differential absorption lidar LEANDRE 2; mesoscale modelling; AROME-WMED; Meso-NH; Mistral/ Tramontane; southerly marine flow; water vapour variability

\section{Introduction}

Mistral and Tramontane are two regional dry winds which are often found to blow in the northwestern Mediterranean basin. In the Gulf of Lion area, Mistral and Tramontane may typically take place when there is a high pressure area in the Bay of Biscay and a low pressure area around the Gulf of Genoa. Mistral is a predominantly northerly flow which typically develops along the Rhône valley (see Figure 1 for geographical locations), primarily associated with the orographic forcing produced by the French Alps and the Massif Central. Tramontane is similar to the Mistral in its causes and effects, but it follows a different corridor (the Aude Valley), blowing between the Pyrenees and the Massif Central and producing a primarily northerly-northwesterly flow. Generally, when a large-scale or a synoptic-scale flow favourably interacts with orography, a lee primary depression and an associated windward high-pressure system are activated. The orographic perturbation breaks the geostrophic balance which prevails at synoptic scale and creates local areas of strong pressure gradient. These pressure gradients provide the acceleration needed to generate the intense local winds, which are often also found far from the orographic region of origin (Campins et al., 1995). When this happens, the air flow between the high and low pressure areas draws in a current of cold air from the north which accelerates through the lower elevations between the foothills of the Alps and the Cévennes. The conditions for a Mistral/Tramontane may be also favourable when a cold rainy front crosses France from the northwest to the southeast as far as the Mediterranean (see discussion for the second case-study reported in this article). Mistral and Tramontane usually blow in winter or spring, though 


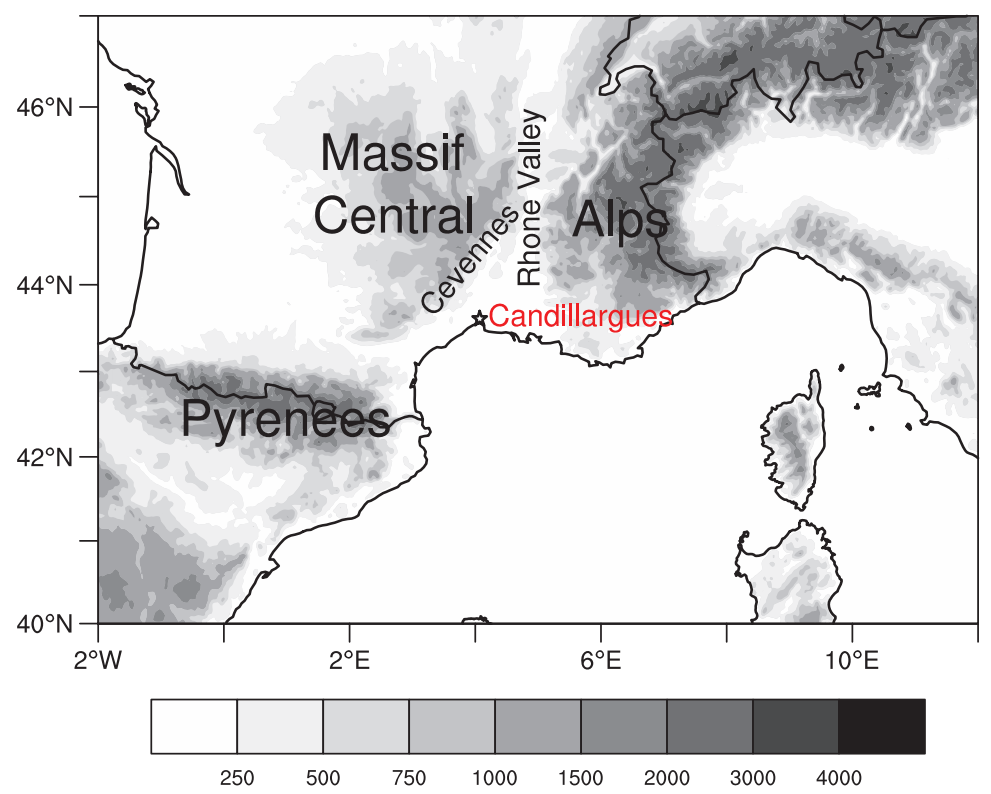

Figure 1. Map of the northwestern Mediterranean basin, with topographic features (m). The star identifies the geographical location of the atmospheric 'supersite' located in Candillargues.

they occur in all seasons. They may last only one or two days, but frequently last several days, and sometimes last more than a week.

Mistral and Tramontane bring cold and dry continental air over the sea and are frequently observed to extend a few hundred kilometres off the coast (Jansa, 1987; Georgelin and Richard, 1996; Drobinski et al., 2001, 2005; Guénard et al., 2005, 2006), and, especially in the winter, generate intense air-sea heat exchanges (Flamant, 2003; Rainaud et al., 2015; Saïd et al., 2016) and sea surface cooling (Schott etal., 1996), which strongly impacts the coastal ocean dynamics (Estournel etal., 2003; Lebeaupin-Brossier et al., 2014).

In southern France, the occurrence of Mistral and Tramontane at the coast is often observed to alternate with southerly marine flows. These marine flows can be either local sea breezes (Bastin etal., 2006) or associated with larger-scale synoptic systems and modified by the coastal mountains and islands. Marine flows transport moist air onshore, sometimes associated with heavy precipitation (Ricard etal., 2012). A sea breeze is a wind developing over bodies of water near land resulting from differences in air pressure, which are generated by the different heat capacity of water and land. The strength of the sea breeze is proportional to the temperature/pressure gradient. Sea-breeze events may superpose with synoptic southerlies at different scales (Delbarre et al., 2005) or compete with weak Mistral (Kalthoff et al., 2005; Saïd etal., 2007). The presence of an opposite wind with a speed exceeding $4-5 \mathrm{~m} \mathrm{~s}^{-1}$ may prevent the sea breeze from developing. During the night, an inverse circulation, known as land breeze, can be observed as the coastal waters become warmer than the nearby land (Ackerman and Knox, 2003).

During the Hydrological Cycle in the Mediterranean Experiment Special Observation Period 1 (HyMeX-SOP1, September-November 2012: Ducrocq et al., 2014) several events when the southerly marine flow broke through and overcame the Mistral/Tramontane flow were observed. The complex interaction between the southerly marine flow and the Mistral/Tramontane events may lead to a rapid transition between the two wind regimes along the coastline (Bastin etal., 2005b, 2006). This interaction significantly affects atmospheric dynamics near the shore, as well as the four-dimensional water vapour variability in the region. Bresson etal. (2012) showed that the location and intensity of coastal heavy precipitation is very sensitive to the wind intensity and humidity content of the marine flow.

In the present article we report measurements performed by the ground-based University of BASILicata Raman lidar system (BASIL: Di Girolamo et al., 2009a) and the airborne differential absorption lidar (DIAL) system LEANDRE 2 (Bruneau etal., 2001a), which are used to illustrate the high time and space variability of the water vapour field associated with the occurrence of three transition events from northerly, primarily Mistral or Tramontane, to southerly marine flow in southeastern France during HyMeX-SOP1. Measurements from these two systems are also used to validate the numerical simulations from the mesoscale models Mesoscale Non-Hydrostatic model (Meso-NH: Lafore et al., 1998) and Application of Research to Operations at Mesoscale - West Mediterranean Sea (AROME-WMED: Fourrié et al., 2015).

This article demonstrates the capability of lidar systems to capture the fast temporal evolution of the vertical and horizontal variability of the water vapour field in the lower troposphere associated with the low-level wind reversals, thus permitting an accurate identification as well as space/time location of the transition events from Mistral/Tramontane to southerly marine flow. This information is of paramount importance for the verification of numerical weather prediction (NWP) models, as in fact a thorough validation of their ability to properly simulate the processes governing the unsteady and inhomogeneous penetration of southerly marine flows in the presence of Mistral/Tramontane flows is strongly required (Bastin et al., 2005a, 2006). The verification of the capability of NWP models to accurately capture these transitions and properly forecast the large vertical and horizontal variability of the water vapour field associated with these events is also important for the assessment of the ability of these models to simulate the water vapour variability associated with heavy precipitation events and therefore properly forecast their occurrence.

The article outline is the following. Section 2 provides a brief illustration of HyMeX-SOP1 and its observation strategy. In section 3 a short description of the Raman lidar system BASIL and the water vapour differential absorption lidar (DIAL) system LEANDRE2 is given, while section 4 briefly describes the mesoscale models Meso-NH and AROME-WMED. Sections 5 and 6 are dedicated to the case-studies on 19/20 September 2012 and 10-12/13-15 October 2012, respectively, with a detailed illustration and discussion of the water vapour and aerosol lidar measurements performed during these low-level wind reversal events, and the corresponding mesoscale model runs. Section 7 reports the results of two specific model sensitivity experiments dedicated to the assessment of the potential role of sea breeze in the case-study on 19/20 September 2012 and the investigation of the source of model result discrepancies between Meso-NH and AROME-WMED observed for this case-study. All results are summarized in section 8 . 


\section{HyMeX and Its Special Observation Period 1}

HyMeX was conceived with the goal of improving the comprehension of the water cycle in the Mediterranean (Drobinski etal., 2014). Within this programme a major field campaign, SOP1, took place in the period September-November 2012 over the northwestern Mediterranean Sea and its surrounding coastal regions in France, Italy and Spain, with a specific focus on the study of heavy precipitation and flashflood events (Ducrocq etal., 2014). The observation strategy of the field experiment was devised to improve knowledge on the following key components leading to heavy precipitation in the region: (i) the marine atmospheric flows that transport moist and conditionally unstable air towards the coasts; (ii) the Mediterranean Sea acting as a moisture and energy source; (iii) the dynamics and microphysics of the convective systems producing heavy precipitation.

The domain of HyMeX-SOP1 was defined to include the regions most favourable to high precipitation events in the western Mediterranean region and within the aircraft flight endurance ranges. Within this large domain, five sites were selected for the deployment of research ground instruments, in addition to the operational meteorological and hydrological ground networks covering the larger SOP1 domain. These are the CévennesVivarais (CV) and the Corsica (CO) sites in southern France, the Central Italy (CI) and Northeastern Italy (NEI) sites, and the Spanish Balearic Islands (BA) site in Menorca (Ducrocq et al., 2014).

As part of the CV site, a set of research instruments was installed in an atmospheric 'supersite' located in Candillargues $\left(43^{\circ} 37^{\prime} \mathrm{N}, 4^{\circ} 04^{\prime} \mathrm{E}\right.$, elevation: $\left.1 \mathrm{~m}\right)$, near the coast and south of the Massif Central. Among these instruments, a wind profiler, a radiometer, a radiosonde launching facility and a variety of radars and lidars were present. The Raman lidar system BASIL, whose measurements are reported in this article, was also deployed in Candillargues.

Three aircraft participated in the field campaign: the French ATR42, the French Falcon20 and the German Do128. The French ATR42, operated by the Service des Avions Instrumentes pour la Recherche en Environnement (SAFIRE), was stationed at Montpellier airport, having the possibility of refuelling in the Balearic Islands or Corsica. The primary mission of the ATR42 was to characterize the water vapour and aerosol inflow feeding heavily precipitating systems. Its main payload consisted of the airborne DIAL LEANDRE 2, capable of profiling water vapour mixing ratio above or beneath the aircraft. The ATR42 payload also included in situ sensors for turbulence measurements, as well as aerosol/cloud microphysics probes for characterizing the environment upstream of the convective systems. The ATR42 performed mostly regional surveys over the Mediterranean Sea. Some ATR42 flights were also dedicated to turbulent flow measurements over the Gulf of Lion and to lidar calibration/validation efforts over the Candillargues supersite. Measurements from LEANDRE 2 represent an important piece of information in the characterization of the transition events from Mistral/Tramontane to southerly marine flow illustrated in the present article.

\section{The water vapour lidars: BASIL and LEANDRE2}

This article reports measurements performed by the groundbased Raman lidar BASIL and the airborne LEANDRE 2 system in the framework of HyMeX-SOP1, that are used to study the spatial-temporal variability of the water vapour field associated with the occurrence of three Mistral/Tramontane to southerly marine flow transition events in southern France. Both systems are very effective in the characterization of water vapour profiles throughout the troposphere both in daytime and night-time conditions, providing accurate and high time- and spaceresolution measurements of the water vapour mixing ratio profile.
Specifically, BASIL was deployed in Candillargues and operated from 5 September to 5 November 2012, collecting more than $600 \mathrm{~h}$ of measurements, distributed over 51 measurement days and 19 Intensive Observation Periods (IOPs). Quick-looks of these datasets are present on the HyMeX-SOP1 website (sop.hymex.org/), under Lidars and Radiometers, while water vapour and particle backscatter data can be downloaded from the HyMeX database (mistrals.sedoo.fr/HyMeX/).

BASIL uses a tripled Nd:YAG laser (single pulse energy power at $355 \mathrm{~nm}$ : $500 \mathrm{~mJ}$, pulse repetition frequency: $20 \mathrm{~Hz}$, average power: $10 \mathrm{~W}$ ) and a Newtonian telescope (primary mirror diameter: $45 \mathrm{~cm}, \mathrm{f} / 2.1$ ). The major feature of BASIL is represented by its capability to perform high-resolution and accurate measurements of atmospheric temperature and water vapour, both in daytime and night-time, based on the application of the rotational and vibrational Raman lidar techniques in the ultraviolet (Di Girolamo et al., 2004, 2006, 2009a; Bhawar et al., 2011). Besides temperature and water vapour, BASIL is also capable of providing measurements of particle backscatter at 355, 532 and $1064 \mathrm{~nm}$, particle extinction at 355 and $532 \mathrm{~nm}$, and particle depolarization at 355 and $532 \mathrm{~nm}$ (Griaznov et al., 2007; Di Girolamo et al., 2009b, 2012a, 2012b).

Concerning water vapour mixing ratio measurements, BASIL provides daytime and night-time profiles with a maximum vertical and temporal resolution of $7.5 \mathrm{~m}$ and $10 \mathrm{~s}$, respectively. The typical daytime precision is $0.2 \mathrm{~g} \mathrm{~kg}^{-1}$ up to $3 \mathrm{~km}$ and $0.3 \mathrm{~g} \mathrm{~kg}^{-1}$ up to $5 \mathrm{~km}$, while the typical night-time precision is $0.05 \mathrm{~g} \mathrm{~kg}^{-1}$ up to $3 \mathrm{~km}$ and $0.005 \mathrm{~g} \mathrm{~kg}^{-1}$ at $10 \mathrm{~km}$, based on an integration time of $5 \mathrm{~min}$ and a vertical resolution of $150 \mathrm{~m}$ (Di Girolamo et al., 2009b). Water vapour mixing ratio measurements by BASIL were calibrated based on the comparison with the radiosondes launched from the lidar site, with the radiosonde launching facility being located approximately $100 \mathrm{~m}$ away from the lidar station. A mean calibration coefficient for water vapour mixing ratio measurements during HyMeX-SOP1 was estimated by comparing BASIL and radiosonde data at all times when BASIL was running (approximately 50 comparisons). Because of the proximity of BASIL to the launching facility, for the purpose of the determination of the calibration coefficient the comparisons were carried out in a vertical region with an extent of approximately $2 \mathrm{~km}$ located just above the lidar station.

During HyMeX-SOP1, LEANDRE2 was operated in zenithand nadir-pointing mode. Details concerning the design of LEANDRE2 and the standard DIAL signal processing procedure are given in Bruneau et al. (2001a, 2001b). The system includes a tunable laser (a flash-lamp-pumped alexandrite laser) whose emission wavelength is tuned upon a water vapour absorption line selected from two rotation-vibration bands in the near infrared $(727-770 \mathrm{~nm})$. The laser operates in a double-pulse, dual-wavelength mode at a $50 \mathrm{~ms}$ time interval, emitting two $50 \mathrm{~mJ}$ successive on-line and off-line pulses with an output linewidth of $1.3 \mathrm{pm}\left(2.4 \times 10^{-2} \mathrm{~cm}^{-1}\right)$ and a spectral purity larger than $99.99 \%$. Within HyMeX-SOP1, LEANDRE2 was operated considering mainly two weak water vapour absorption bands, centred at 730.4 and $731.2 \mathrm{~nm}$, optimal for water vapour retrievals in atmospheres characterized by moderate integrated water vapour contents. The spectral positioning is controlled in real time by a wave-meter with an absolute accuracy of $5 \times 10^{-3} \mathrm{~cm}^{-1}$. The receiver is developed around a $30 \mathrm{~cm}$ aperture telescope with a $3.5 \mathrm{mrad}$ field of view and a $1 \mathrm{~nm}$ filter bandwidth (see also Table 1). A differential absorption lidar uses two different laser wavelengths which are selected so that one of the wavelengths is absorbed by water vapour while the other wavelength is not. The derivative of the logarithm of the ratio of the on- and off-line backscatter signals is used to determine the water vapour density, based on the knowledge of the water vapour absorption crosssections at the on-line and off-line wavelengths. The absorption lines characteristics (strength, width, etc.) are known from highaccuracy laboratory data (e.g. the HITRAN database). Because the ratio of the on- to the off-line backscatter signal is used 
Table 1. Summary table of LEANDRE 2.

\begin{tabular}{lc}
\hline Laser source & Flash-lamp-pumped alexandrite laser \\
Spectral range & $727-770 \mathrm{~nm}$ \\
Pulse energy & $2 \times 50 \mathrm{~mJ}$ \\
Repetition rate & $10 \mathrm{~Hz}$ \\
Double-pulse temporal separation & $50 \mathrm{~ms}$ \\
Linewidth & $1.3 \mathrm{pm}$ \\
Spectral positioning accuracy & $<0.25 \mathrm{pm}$ \\
Spectral purity & $99.99 \%$ \\
Telescope diameter & $30 \mathrm{~cm}$ \\
Field of view & $1.5-8 \mathrm{mrad}$ \\
Photomultiplier quantum efficiency & $4 \%$ \\
Digitizer & $12 \mathrm{bits} / 10 \mathrm{MHz}$ \\
\hline
\end{tabular}

to assess the water vapour density, the instrumental parameters affecting the signal at both wavelengths cancel out. Furthermore, if the on-line and off-line wavelengths are selected so that they are only separated by a few $\mathrm{cm}^{-1}$ (in order for the backscatter contribution from aerosols, clouds or clear skies to be the same at both wavelengths), then simultaneous (or quasi-simultaneous) measurements of the on- and off-line backscatter signals allow the determination of the water vapour number density profile without the need for exogenous calibration. Consequently, the DIAL technique is a self-calibrated technique. LEANDRE2 allows water vapour mixing ratio measurements to be performed with a precision ranging from less than $0.1 \mathrm{~g} \mathrm{~kg}^{-1}$ at $4.5 \mathrm{~km}$ above sea level to less than $0.4 \mathrm{~g} \mathrm{~kg}^{-1}$ near the surface for an along-beam resolution of $150 \mathrm{~m}$ and accumulation of 100 individual profiles, corresponding to an along-track resolution of approximately $1 \mathrm{~km}$ for an ATR42 flying speed of $100 \mathrm{~m} \mathrm{~s}^{-1}$. Systematic errors associated with the LEANDRE2 system are described in Bruneau et al. (2001b) and are typically not exceeding $0.1 \mathrm{~g} \mathrm{~kg}^{-1}$. During HyMeX-SOP1, LEANDRE2 performed over 60 flight hours: 8 of which were supported by the European Facility for Airborne Research project 'WaLiTemp' and the reminder as part of the HyMeX-SOP1 endowment supported by the Mediterranean Integrated STudies at Regional and Local Scales (MISTRALS) programme.

\section{Mesoscale models: Meso-NH and AROME-WMED}

Numerical simulations considered in this article were performed with two non-hydrostatic cloud-resolving models: Meso-NH and AROME-WMED. The former is a research model developed by Laboratoire d'Aérologie and CNRM-GAME (Lafore et al., 1998), while the latter derives from the French operational numerical weather prediction system AROME (Seity et al., 2011). AROMEWMED was especially set up for the needs of HyMeX and more details can be found in Fourrié et al. (2015). Both models were run with a $2.5 \mathrm{~km}$ horizontal resolution to cover approximately the same geographical domain encompassing the whole western Mediterrean basin $\left(34^{\circ} \mathrm{N}-48^{\circ} \mathrm{N} / 9^{\circ} \mathrm{W}-20^{\circ} \mathrm{E}\right)$. Though based upon different dynamical cores, Meso-NH and AROME-WMED make use of the same physical package: 1.5-order closure turbulence parametrization (Cuxart et al., 2000), five-class cloud microphysics scheme (Caniaux et al., 1994; Pinty and Jabouille, 1998) and mass-flux shallow convection scheme (Pergaud et al., 2009). The SURFEX surface model (Masson et al., 2013) describes the exchanges of energy and water between the atmosphere and different surface types (natural land surface, urban area, ocean and lake); this model includes the Interactions between Soil, Biosphere and Atmosphere (ISBA) surface scheme (Noilhan and Planton, 1989) for natural land surface. During HyMeX-SOP1 both models were run in real time and a $48 \mathrm{~h}$ (AROME-WMED) or $30 \mathrm{~h}$ (Meso-NH) forecast was issued every day starting from 0000 UTC. Another essential difference between the two sets of forecasts lies in their initial and coupling fields. They were obtained from the European Centre for Medium-Range Weather Forecasts in the case of Meso-NH. For AROME-WMED, the lateral boundary coupling fields were obtained from the French operational global forecast model Action de Recherche Petite Echelle Grande Echelle (ARPEGE) whereas the initial conditions are issued from the own AROME three-dimensional variational data assimilation cycle. The AROME-WMED analyses assimilated each $3 \mathrm{~h}$ all conventional observations (radiosoundings, surface observations, buoys and aircraft), operational wind profilers, Global Positioning System (GPS) zenith total delays from the EUMETNET EIG GNSS (Global Navigation Satellite System) water vapour programme (E-GVAP) network, Doppler winds and reflectivity from Météo-France weather radars over France, scatterometer winds and satellite radiances. Some additional observations available during HyMeX-SOP1 and distributed through the Global Telecommunication System (GTS) were also assimilated in real time in AROME-WMED. Among these, the radiosondes launched from Candillargues. Moreover, temperature and wind from boundary-layer pressurized balloons were also used in the AROME-WMED analysis during HyMeXSOP1. Thanks to its own assimilation system, AROME-WMED was able to represent smaller-scale features in its initial conditions as compared to the Meso-NH initial fields, which were obtained by simple interpolation from the larger-scale ECMWF outputs.

\section{Case-study on $19 / 20$ September 2012}

Figure 2 illustrates the time evolution of the wind direction and speed, relative humidity and temperature for the period from 0000 UTC 19 September 2012 to 0000 UTC 21 September 2012 from a meteorological surface station located in Candillargues. The figure also reports these same quantities as simulated by Meso-NH and AROME-WMED. Gradients of surface wind direction and speed, relative humidity and temperature are considered to identify the transitions from Mistral/Tramontane to predominantly southerly marine flow and vice versa. Specifically, a progressive change in surface wind direction from a predominantly northerly to a predominantly southerly flow identifies transitions from Mistral/Tramontane to marine flow, while an opposite change identifies transitions from marine flow to Mistral/Tramontane. Usually, transitions from Mistral/Tramontane to southerly marine flow are characterized by a progressive change in surface wind speed from values in the range $7-15 \mathrm{~m} \mathrm{~s}^{-1}$ to values typically not exceeding $2-3 \mathrm{~m} \mathrm{~s}^{-1}$, while an opposite change characterizes transitions from southerly marine flow to Mistral/Tramontane. The presence of a Mistral/Tramontane flow can typically be distinguished from a generic northerly/northwesterly flow because of the simultaneous occurrence of the large-scale meteorological conditions illustrated in the Introduction and the presence of wind speeds exceeding $7 \mathrm{~m} \mathrm{~s}^{-1}$.

The observed variability of surface wind direction and speed, relative humidity and temperature depicted in Figure 2 allows us to identify the southeasterly marine flow onset from a previous weak Mistral/Tramontane event starting around 1000 UTC 20 September 2012, with wind direction progressively veering from about 0 to about $150^{\circ}$ (from northerly to southeasterly), wind speed progressively decreasing from approximately $6-8$ to $2-3 \mathrm{~m} \mathrm{~s}^{-1}$ and relative humidity and temperature progressively increasing from 30 to $90 \%$ and from 11 to $24^{\circ} \mathrm{C}$, respectively. Water vapour mixing ratio (not shown in Figure 2) progressively increases from $4-5$ to $12-13 \mathrm{~g} \mathrm{~kg}^{-1}$. Meso-NH and AROMEWMED reveal a very good capability to reproduce the surface wind direction and speed, relative humidity and temperature during this low-level wind reversal event, with deviations not exceeding $30^{\circ}, 2 \mathrm{~m} \mathrm{~s}^{-1}, 20 \%$ and $2^{\circ} \mathrm{C}$, respectively. A closer look into the $10 \mathrm{~m}$ wind field analyses from AROME-WMED (Figure 3 ) reveals that at 1800 UTC 19 September 2012 both Tramontane (northwesterly) and Mistral (northerly) are present (a), while at 0600 UTC 20 September 2012 only the Mistral is blowing (b). Later during the day (at 1800 UTC, Figure 3(c)) an easterly flow is seen along the French coastline to go around the southern Alps and to veer to the north over the Gulf of Lion, 

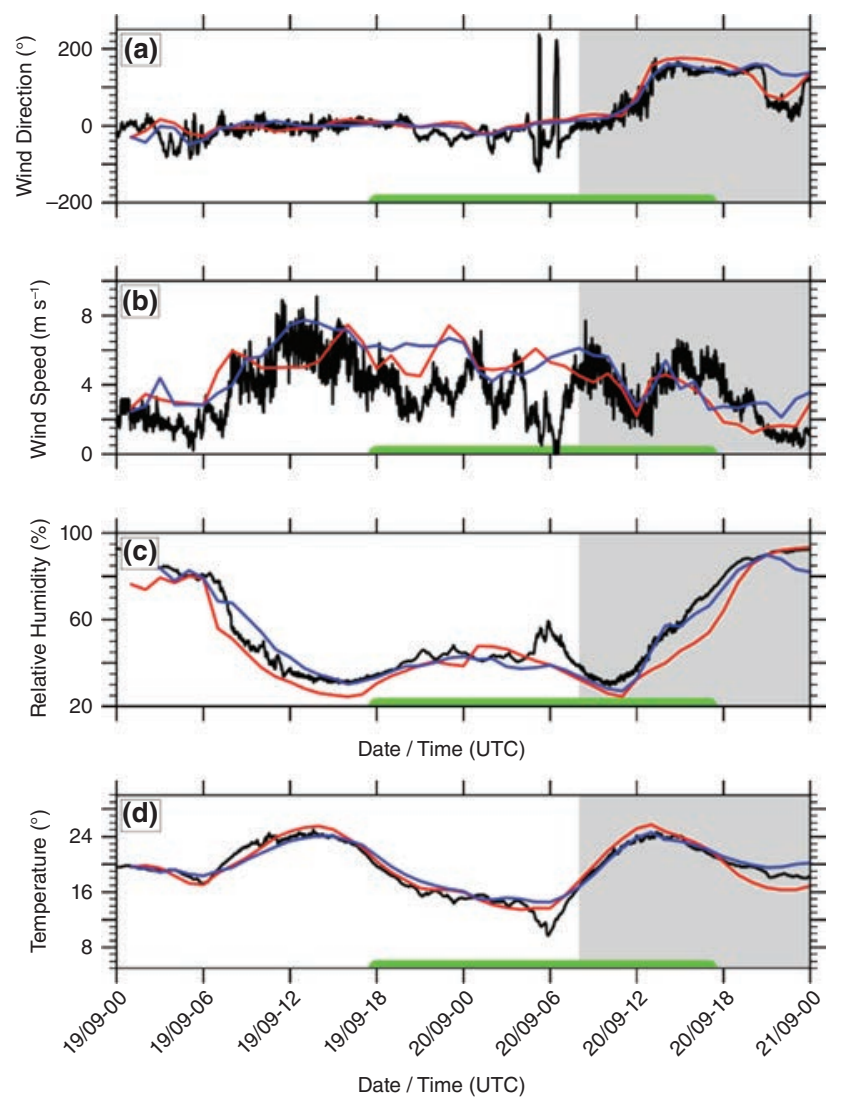

Figure 2. Time evolution of (a) wind direction and (b) speed, (c) relative humidity and (d) temperature, for the period 19-21 September 2012 as measured by the surface meteorological station located in Candillargues (black lines) and as simulated by Meso-NH and AROME-WMED (red lines and blue lines, respectively). The green line on the bottom axis underlines the time interval for which the water vapour measurements from BASIL are available. Shaded areas mark the transition to southerly flow in Candillargues.

thus generating the observed southeasterly marine flow observed at Candillargues (Figure 2(a)). This southeasterly marine flow is most probably the combination of a sea-breeze event (southern component) with a synoptic easterly flow (see specific sensitivity study in section 7), leading to a significant penetration inland and intensification of the low-level southerly flow (Bastin et al., 2005b; Delbarre et al., 2005). Similarly to what was described in Bastin et al. (2005b), in Bastin and Drobinski (2005) and in Drobinski et al. (2005), because of the absence of an opposite northerly flow, the sea-breeze flow could penetrate inland over a horizontal range of more than $150 \mathrm{~km}$ (Figure 3(c)). Figure 3(c) also reveals that, near the coastline, the sea breeze is locally perpendicular to the coastline shape, similarly to what was described in Banta (1995), Bastin et al. (2005b) and Lemonsu et al. (2006).

Figure 4(a) illustrates the time evolution of the water vapour mixing ratio as measured by BASIL over a $24 \mathrm{~h}$ time period from 1700 UTC 19 September 2012 to 1700 UTC 20 September 2012. This figure reveals the arrival of the moist air in Candillargues associated with the southeasterly marine flow, with a strong gradient in the water vapour field, starting from approximately 0930 UTC. During the Mistral/Tramontane flow, before the arrival of the humid layer, the mixing ratio values in the boundary layer are not exceeding $4-5 \mathrm{~g} \mathrm{~kg}^{-1}$ (in good agreement with the above reported surface data). The humid layer associated with the marine flow is found to extend up to the boundary-layer top (approximately $1.5 \mathrm{~km}$ ), with mixing ratio values as large as $11-12 \mathrm{~g} \mathrm{~kg}^{-1}$ (again, in good agreement with surface data). The limited depth of the moist layer is most probably the effect of the low-pressure system in the Gulf of Genoa being located near the surface only. Above the boundary-layer top, the water vapour variability associated with the marine flow arrival is limited, with mixing ratio values not exceeding $3 \mathrm{~g} \mathrm{~kg}^{-1}$, both before and after the arrival of the flow. This is because the marked wind reversal is taking place only within the boundary layer (from northerly to southeasterly flow, with a direction change of approximately $150^{\circ}$, i.e. an almost complete reversal); and it is characterized by a strong wind speed gradient (from $18-20$ to $3-5 \mathrm{~m} \mathrm{~s}^{-1}$ ), while it is only partially extending to the free troposphere (the wind transition above the planetary boundary layer $(\mathrm{PBL})$ is from northerly-northwesterly to easterly and it is characterized by a much weaker wind speed gradient, $5-8$ to $3-5 \mathrm{~m} \mathrm{~s}^{-1}$ ). In this respect it is to be pointed out that BASIL is characterized by a limited capability to measure low humidity contents and their variability at these heights as a result of its limited measurement precision (large statistical errors) during this portion of the day (late morning), characterized by large solar irradiance values and the presence of clouds at the top of the boundary layer (cloud base at $1.2-1.5 \mathrm{~km}$ ); these latter extinguish the laser beam and prevent it from receiving detectable lidar echoes from above. Consequently, any variability in the small humidity levels present above the boundary-layer top may be only partially captured because of the poor measurement sensitivity at these heights.

The increase in water vapour mixing ratio associated with the low-level wind reversal is quite abrupt and marked (more than in the other two case-studies reported in this article): in the upper portion of the boundary layer (around $1.2 \mathrm{~km}$ ) water vapour mixing ratio values increase by a factor of approximately 4 from $\sim 3$ to $\sim 12 \mathrm{~g} \mathrm{~kg}^{-1}$ in the time interval $0900-1000$ UTC on 20 September 2012 (i.e. $9 \mathrm{~g} \mathrm{~kg}^{-1} \mathrm{~h}^{-1}$ ), while at lower levels the transition appears more gradual. As mentioned above, the more marked increase in water vapour mixing ratio in this casestudy with respect to those discussed in the following sections is most probably related to the onset of the sea breeze, which is superimposed to a synoptic flow. The humid layer is first revealed in the upper portion of the boundary layer and then it is found to progressively fill the boundary layer, extending down to the surface. The earlier arrival of the humid air in the upper portion of the boundary layer and its later arrival at lower levels can be interpreted based on the measurements performed by the ultrahigh frequency (UHF) wind profiler located in Candillargues (Figure 4(c)), which provides wind profile measurements with a temporal resolution of $15 \mathrm{~min}$. High-resolution wind profiles reveal that, starting at 0930 UTC, a first wind shift is observed to occur at $1 \mathrm{~km}$, with air blowing from the east, while it was still blowing from the northeast at 0830 and 0900 UTC. The easterlies first reached the $1 \mathrm{~km}$ level since the curvature radius of the air deflected by the orography is smaller at $1 \mathrm{~km}$ than it is near the surface. Then the wind progressively turns south, first at $1 \mathrm{~km}$ and gradually in the whole layer, and the moist marine air progressively fills the boundary layer extending down to surface in Candillargues. This explains why the tongue of marine air detected by BASIL is first found to occur at $1 \mathrm{~km}$.

Figure 4(b) illustrates the time evolution of the range-corrected signal at $532 \mathrm{~nm}$ as measured by BASIL over the same time period considered in Figure 4(a). The figure reveals the presence, shortly after the low-level wind reversal, of a drastic change in particle backscatter caused by the arrival of an aerosol-laden air mass associated with the southeasterly marine flow. This change in particle backscatter is superimposed on its diurnal variability associated with the development of the boundary layer, which starts building up approximately at the time when the wind reversal takes place. The warmer and more humid air advected by the marine flow is characterized by a larger aerosol loading, predominantly of maritime origin, which is replacing the colder and drier air advected by the Mistral/Tramontane flow, primarily loaded with continental aerosol. Particle backscatter is found to increase by approximately $50 \%$ in amplitude as a result of the marine flow arrival. The increase in the range-corrected signal may also be partially ascribable to aerosol swelling (hygroscopicity) and changes in its optical properties as a result of humidification (Di Girolamo et al., 1999). As for the water vapour, the aerosol layer is first revealed in the upper portion of the boundary layer and then is found to progressively extend down to the surface, 
2012091918 UTC

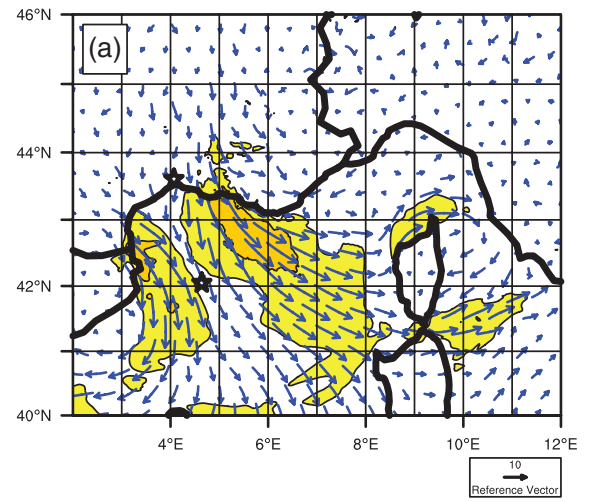

2012092006 UTC

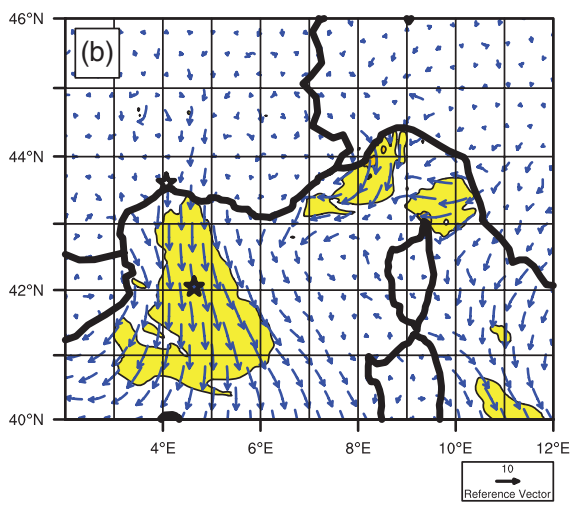

2012092018 UTC

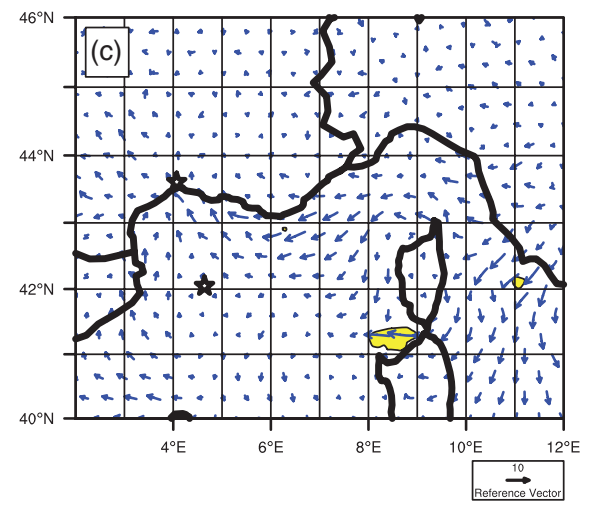

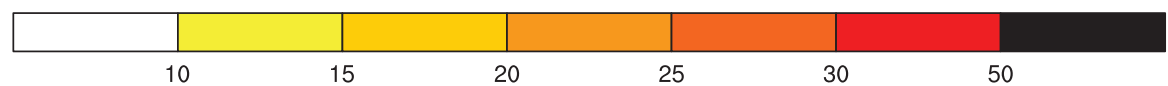

Figure 3. AROME-WMED analyses for $10 \mathrm{~m}$ wind field $\left(\mathrm{m} \mathrm{s}^{-1}\right.$ ) at (a) 1800 UTC 19 September, (b) 0600 UTC 20 September, and (c) 1800 UTC 20 September 2012. The two distinct plumes in (a) identify Tramontane in the west, and Mistral in the central portion of the figure.
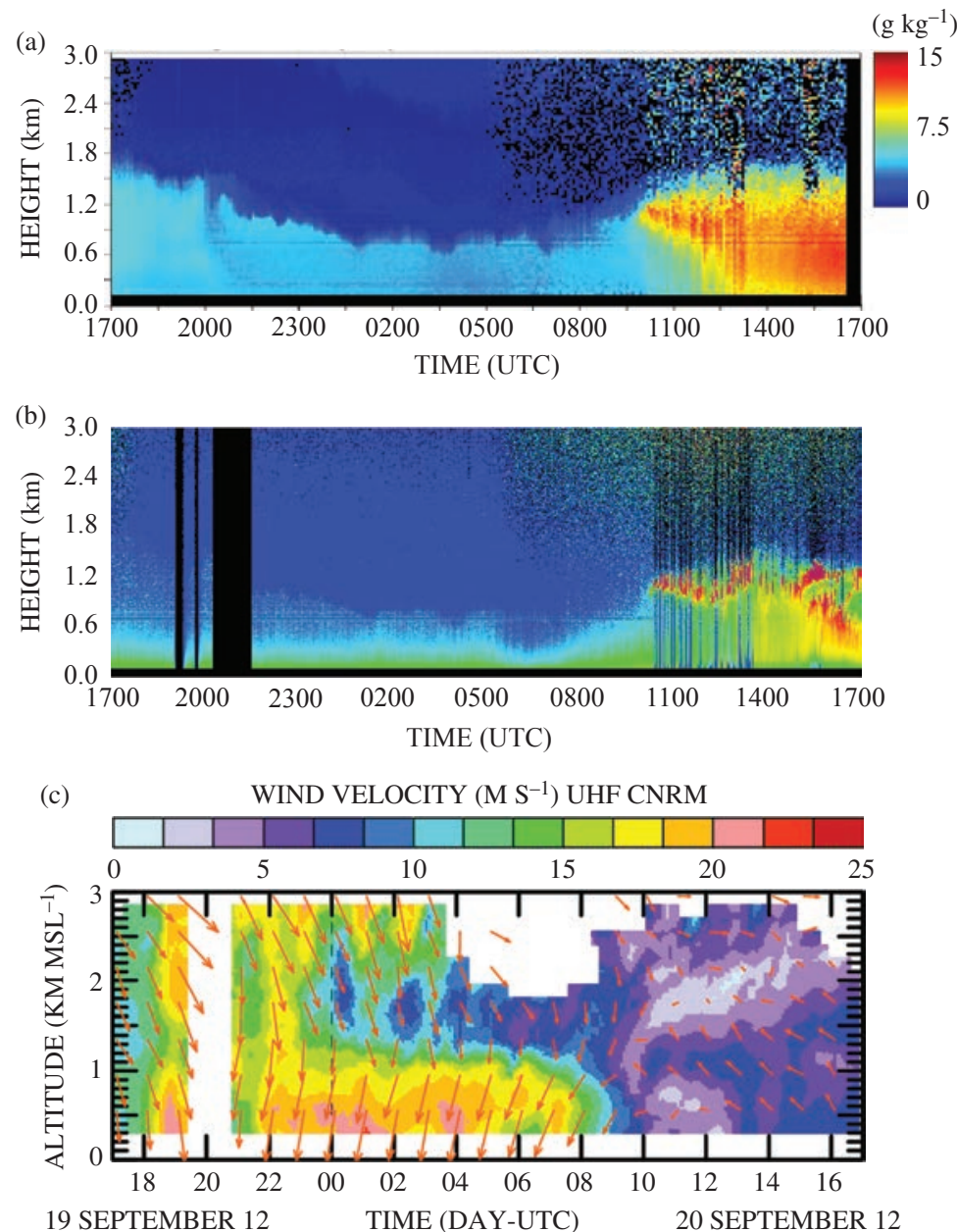

UHF-CNRM CAND (hm,5beams,4kW,375m,15mn,mean:30mn)

Figure 4. Time evolution of (a) the water vapour mixing ratio $\left(\mathrm{g} \mathrm{kg}^{-1}\right)$ and (b) the range-corrected signal at $532 \mathrm{~nm}$ as measured by BASIL, and (c) the wind speed $\left(\mathrm{m} \mathrm{s}^{-1}\right)$ and direction as measured by the UHF wind profiler, over the $24 \mathrm{~h}$ time period from 1700 UTC 19 September to 1700 UTC 20 September 2012 . As the range-corrected signal is expressed in arbitrary units no colour legend is introduced for this quantity as the colour legend for water vapour mixing ratio can be used to identify its relative changes.

completely filling the boundary layer. Clouds at the top of the boundary layer are also observed to form starting at 1030 UTC 20 September 2012 (reddish points in the figure).

Figure 5 illustrates the time evolution of the water vapour mixing ratio as simulated by the mesoscale models AROME-WMED and Meso-NH, together with the model-tomodel absolute difference, over the same time period considered in Figure 4. Meso-NH and AROME-WMED forecasts are provided with hourly time steps. Both Meso-NH and AROMEWMED properly simulate the time-height structure of the humidity field observed by BASIL, reproducing the arrival of the humid air in the boundary layer with similar mixing ratio values $\left(8-12 \mathrm{~g} \mathrm{~kg}^{-1}\right)$ for AROME-WMED and slightly lower values (in the range $6-8 \mathrm{~g} \mathrm{~kg}^{-1}$ ) for Meso-NH. Meso-NH is found to be drier than AROME-WMED and BASIL in the present case-study, but it is not in the other two case-studies reported thereafter. A possible explanation for Meso-NH being drier than AROMEWMED can be found in the initial conditions, which, as already mentioned above, for the two models are derived from different analysis systems (see sensitivity study in section 7 ). The two 

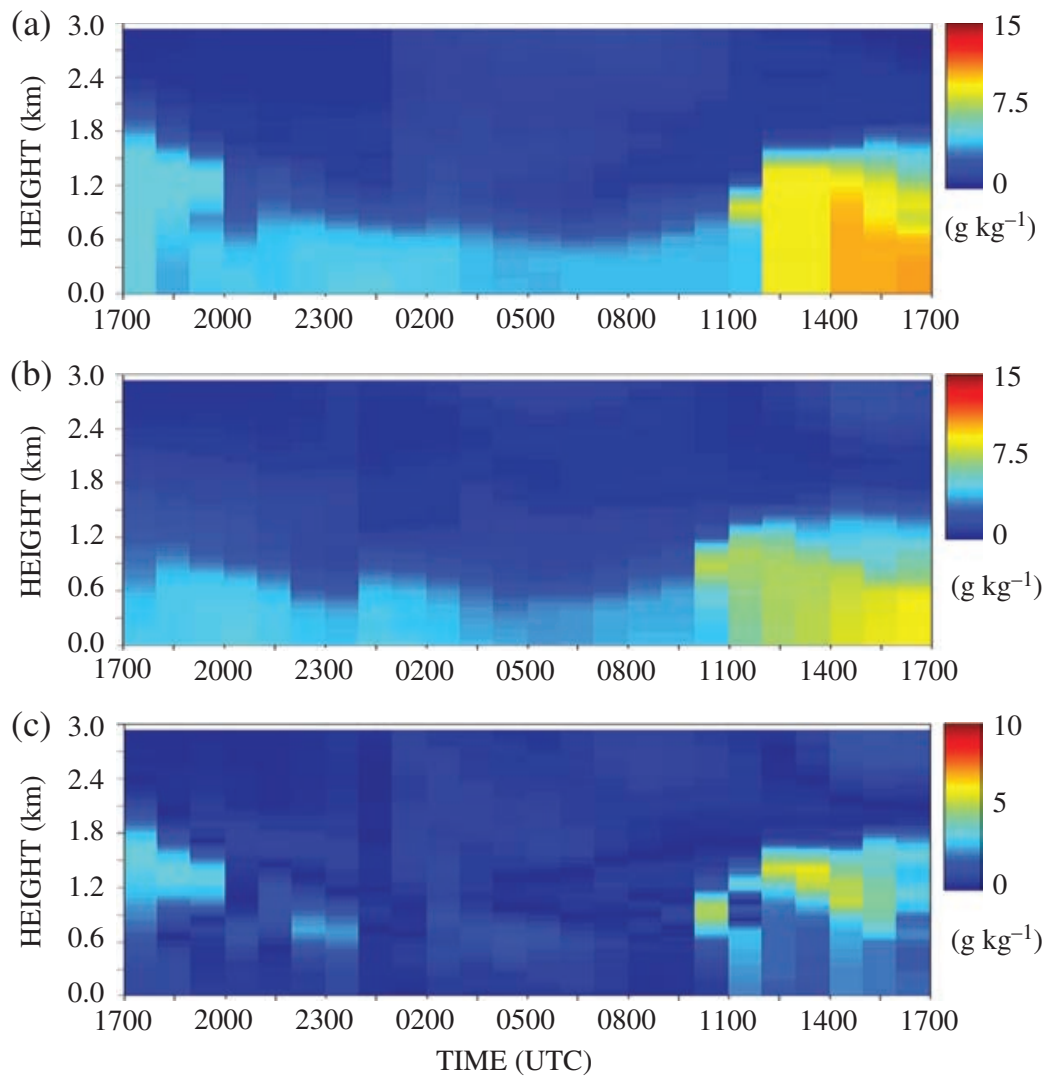

Figure 5. Time evolution of the water vapour mixing ratio $\left(\mathrm{g} \mathrm{kg}^{-1}\right)$ as simulated by the mesoscale models (a) AROME-WMED and (b) Meso-NH, over the $24 \mathrm{~h}$ time period from 1700 UTC 19 September to 1700 UTC 20 September 2012. (c) The model-to-model difference $\left(\mathrm{g} \mathrm{kg}^{-1}\right)$.

models are found to mix the boundary layer approximately $1 \mathrm{~h}$ after the wind reversal, whereas a complete mixture is observed in water vapour mixing ratio data from BASIL only after 2 or $2.5 \mathrm{~h}$ Figure 5(c) allows us to identify the water vapour small-scale differences between the two models, with larger values primarily found in the proximity of the abrupt increase of the humidity content associated with the arrival of the sea breeze, as a result of Meso-NH being drier than AROME-WMED. The depth of the moist layer also seems to be slightly different for the two models, with the estimate by AROME-WMED being in better agreement with BASIL (moist layer extending for both up to approximately $1500 \mathrm{~m}$ ) than the one from Meso-NH (moist layer extending up to approximately $1300 \mathrm{~m}$ ).

The bias and root-mean-square (RMS) deviation between BASIL and the two mesoscale models have also been computed (Figure 6). For the purpose of this computation we considered the $15 \mathrm{~min}$ average profiles of BASIL data centred on the times of the model profiles. To compute the deviations, model profile data have been interpolated to the altitude levels of BASIL data. Bias and RMS deviations have been computed in the altitude interval from 0.5 to $5.5 \mathrm{~km}$, with $0.5 \mathrm{~km}$ steps. Profiles of mean bias and RMS deviation were obtained considering all 24 profile-to-profile intercomparisons of Meso-NH vs. BASIL and AROME-WMED vs. BASIL. Please notice that, while the considered range of variability for the relative bias and RMS deviation is the same for Meso-NH and AROME-WMED ( -30 to $240 \%$, Figure 6(b) and $(d)$ ), in order to properly display the variability of the absolute bias and RMS deviation, the range of variability for the $x$-axis in Figure 6(a) and (c) is different for AROME-WMED $\left(-1\right.$ to $\left.1 \mathrm{~g} / \mathrm{kg}^{-1}\right)$ and Meso-NH ( -2 to $\left.2 \mathrm{~g} \mathrm{~kg}^{-1}\right)$. Within the boundary layer, values of the mean absolute bias are found to be smaller than $\pm 0.6 \mathrm{~g} \mathrm{~kg}^{-1}$ for the comparison of AROME-WMED vs. BASIL, whereas they are smaller than $\pm 1.25 \mathrm{~g} \mathrm{~kg}^{-1}$ for the comparison of Meso-NH vs. BASIL. Above the boundary-layer top, values of the mean absolute bias are smaller than $0.3 \mathrm{~g} \mathrm{~kg}^{-1}$ for both models. The mean absolute bias between Meso-NH and BASIL is maximum $\left(-1.25 \mathrm{~g} \mathrm{~kg}^{-1}\right)$ at the boundary-layer top, which is reflecting the differences in the moist-layer height between the two. Values of the mean relative bias are found to be quite large (as large as 130\%) in the proximity of the boundary-layer top and above it, these large values being the result of the inclusion in the comparison of the small mixing ratio values $\left(2-3 \mathrm{~g} \mathrm{~kg}^{-1}\right)$, which are found to characterize the very dry region in the proximity and above the boundary-layer top. Values of the RMS deviation between BASIL and the two mesoscale models are slightly larger than the bias values, which indicate that the effect on RMS deviation associated with the statistical uncertainty affecting BASIL measurements is rather small. Besides the mean bias and RMS deviation, in order to assess the degree of correlation between BASIL and the two models, the correlation coefficient has also been estimated. The correlation coefficient of AROME-WMED vs. BASIL is found to be 0.99, while that of Meso-NH vs. BASIL is found to be 0.97 .

It is to be pointed out that values of mean bias decrease, especially in the PBL, if mixing ratio profiles collected during the arrival of the moist and warm marine air and characterized by a large and abrupt increase of the humidity content are removed from the computation (i.e. mixing ratio profiles associated with the Mistral/Tramontane regime only are considered in the computation). Concerning the comparison of AROMEWMED/Meso-NH vs. BASIL, the mean absolute bias is found to be less than $\pm 0.6 / 1.25 \mathrm{~g} \mathrm{~kg}^{-1}$ at all heights if all 24 profiles are considered, while it gets smaller than $\pm 0.4 / 0.7 \mathrm{~g} \mathrm{~kg}^{-1}$ if only the first 17 profiles before the arrival of the marine air are considered in the computation. Similarly, the mean relative bias is as large as $130 / 120 \%$ at the PBL top if all 24 profiles are considered, while it remains smaller than $100 \%$ if only the first 17 profiles are considered. The discussed results reveal the good capability of both mesoscale models in forecasting the water vapour variability associated with the transition events from Mistral/Tramontane to southerly marine flow. However, in this specific case-study Meso- $\mathrm{NH}$ fails in accurately quantifying the amplitude of this transition. 

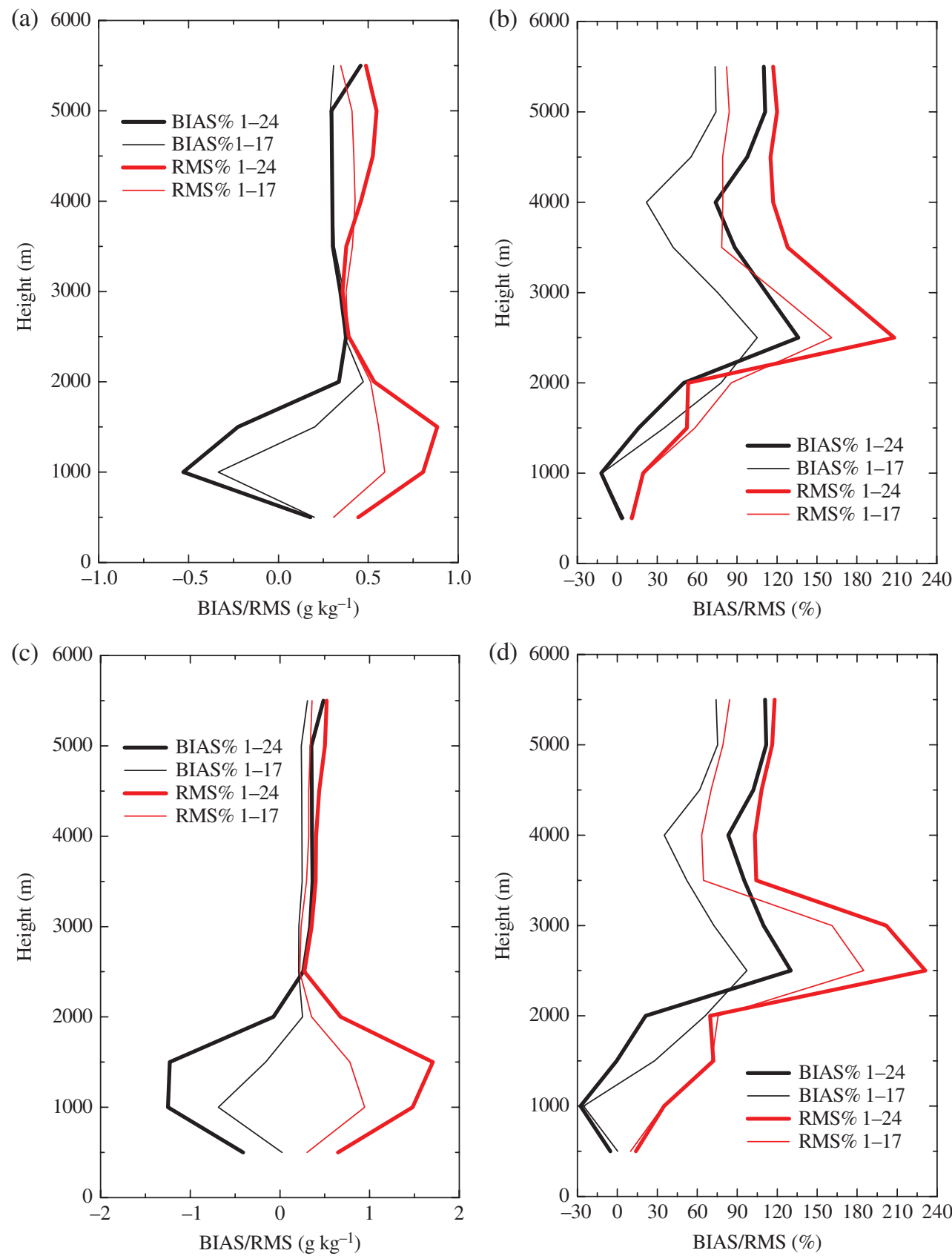

Figure 6. Mean bias and RMS deviation profiles (a,b) between BASIL and AROME-WMED and (c,d) between BASIL and Meso-NH, for the case-study 19/20 September 2012. Panels (a) and (c) illustrate the mean absolute bias and RMS deviation profiles ( $\mathrm{g} \mathrm{kg}^{-1}$ ), while (b) and (d) illustrate the mean relative (or percentage) bias and RMS deviation profiles (\%). Mean profiles are obtained considering all profiles (profiles 1-24), or only those profiles before the arrival of the humid and warm sea-breeze air (profiles 1-17).

\section{Case-studies within the period 9-17 October 2012}

\subsection{Case-study on 10-12 October 2012}

During the period 9-17 October 2012 several flow transitions took place over southern France. Figure 7 illustrates the time evolution of wind direction and speed, relative humidity and temperature over the period from 0000 UTC 9 October 2012 to 0000 UTC 17 October 2012 as measured by the surface meteorological station in Candillargues and simulated by Meso-NH and AROME-WMED. A first wind reversal episode occurred around 0000 UTC on 11 October 2012 when a transition from a weak northwesterly to a predominantly southerly marine flow was observed, accompanied by a significant change in wind direction and speed (from 300 to $200^{\circ}$, i.e. northwesterly to south/southwesterly, and 3 to $1 \mathrm{~m} \mathrm{~s}^{-1}$, respectively). The corresponding changes in relative humidity and air temperature at the surface $(70-80 \%$ and $17-23^{\circ} \mathrm{C}$, respectively) are limited possibly caused by the limited penetration of the southerly marine flow inland. It is to be noticed that the change in relative humidity is partially masked by the temperature increase associated with the diurnal cycle. A more marked change is observed in water vapour mixing ratio (not shown in the figure), with values progressively increasing from 10 to $13.5 \mathrm{~g} \mathrm{~kg}^{-1}$. However, this transition cannot be considered as a transition from a Mistral/Tramontane flow as in fact the wind speed before the transition is only $3 \mathrm{~m} \mathrm{~s}^{-1}$. A subsequent low-level wind reversal associated with a southwesterly $\left(200^{\circ}\right)$ to westerly $\left(260^{\circ}\right)$ Mistral flow transition is observed around 2100 UTC on 11 October 2012, with the flow becoming progressively northwesterly $\left(300^{\circ}\right)$ during the day on 12 October. Meso-NH and AROMEWMED well reproduce the measured values of the surface wind direction and speed, relative humidity and temperature during these low-level wind reversal events, with deviations - except for a few points - not exceeding $20^{\circ}, 2 \mathrm{~m} \mathrm{~s}^{-1}, 15 \%$ and $2{ }^{\circ} \mathrm{C}$, respectively. The $10 \mathrm{~m}$ wind fields from AROME-WMED 3hourly analyses (Figure 8) reveal that at 1200 UTC 10 October 2012 a weak northwesterly flow is present, at 1200 UTC 11 October 2012 very weak winds are analysed over the Gulf of Lion with 

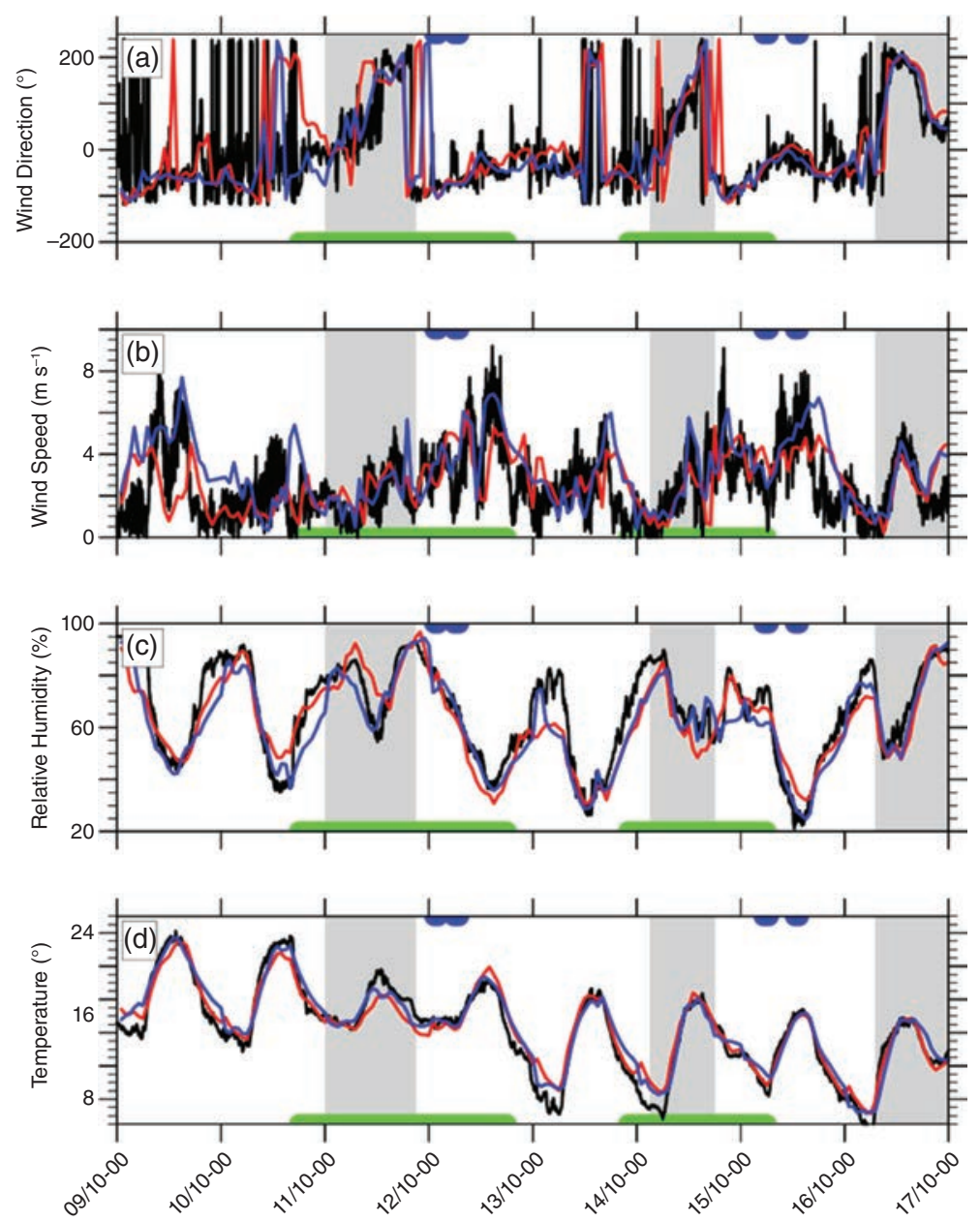

Date / Time (UTC)

Figure 7. Time evolution of the (a) wind direction and (b) speed, (c) relative humidity and (d) temperature, for the period 9-17 October 2012 as measured by the surface meteorological station located in Candillargues (black lines) and as simulated by Meso-NH and AROME-WMED (red lines and blue lines, respectively). Periods corresponding to southerly flows are indicated by grey shading. The green line on the bottom axis underlines the time interval for which the water vapour measurements from BASIL are available. The blue dots at the top axis indicate the time interval for which the LEANDRE II measurements are available.

southerly winds at Candillargues, and at 1200 UTC 12 October 2012 a northwesterly Tramontane-like flow is well established. However, assuming that the sea temperature is rather steady, the progressive decrease in the maximum surface temperature through the period 10-12 October 2012, probably linked to an evolution of the synoptic conditions, and the progressive increase in the minimum surface temperature, associated with cloudy conditions, can explain the less favourable conditions for seabreeze development in this case-study with respect to the one on 19/20 September 2012.

Figure 9(a) illustrates the time evolution of the water vapour mixing ratio as measured by BASIL over a $48 \mathrm{~h}$ time period from 1800 UTC 10 October 2012 to 1800 UTC 12 October 2012. In the early part of this period, northwesterly winds are weak $\left(3 \mathrm{~m} \mathrm{~s}^{-1}\right)$ because of the lack of a strong pressure gradient between the Bay of Biscay and the Gulf of Genoa and a related orographically induced channelling in the Rhône valley with deflection of the westerlies into the valley. Later in the day, a trough was affecting the northwestern Mediterranean Sea, inducing a south/southwesterly flow with a convergence zone moving from Catalonia to the Cévennes-Vivarais region. Thunderstorms and mesoscale convective systems (MCSs) were present in the afternoon and evening on 11 October 2012, inducing significant local rainfall. Figure 9(a) reveals the arrival of the moist air in Candillargues starting at approximately 0500 UTC on 11 October 2012, which is brought by the southwesterly flow. BASIL data indicate that the southwesterly flow brings increasing amounts of moisture to Candillargues as time passes until the northwesterly wind sets in (around 2100 UTC on 11 October 2012) and starts bringing drier air with time. The water vapour mixing ratio within the boundary layer is found to change from values of $9-10 \mathrm{~g} \mathrm{~kg}^{-1}$ to values of $14-15 \mathrm{~g} \mathrm{~kg}^{-1}$ with the arrival of the humid air brought by the southwesterly flow (in good agreement with the above reported surface data). In this case a less marked increase in water vapour mixing ratio is observed within the boundary layer with respect to the case-study on 19/20 September 2012. This smaller humidity gradient is the result of the transition from a weak northwesterly flow to a synoptic-scale south/southwesterly flow induced by the trough, which is not accompanied by the presence of a sea-breeze event. An increase of surface temperature is observed during the southwesterly flow (Figure $7(\mathrm{~d})$ ), primarily associated with the temperature diurnal cycle. The advected maritime air is partially damping this increase as in fact the maximum surface temperature appears to be strongly reduced with respect to the previous days (maximum surface temperature is $23^{\circ} \mathrm{C}$ on this day, while it was $28^{\circ} \mathrm{C}$ on 9 and 10 October 2012). An increase of temperature throughout the boundary layer, associated with the approaching thunderstorms and MCSs, was also revealed by BASIL (which also has a temperature-profiling capability) and the co-located microwave radiometer (not shown here). Measurements were stopped during the time interval from 1700 to 1930 UTC on 11 October 2012 because of a rain event associated with an MCS which was mainly taking place offshore, but was also affecting the coastal areas. Water vapour mixing ratio values suddenly dropped after 2100 UTC on 11 October 2012, when the wind turned west. Water vapour mixing ratio kept progressively decreasing afterwards as a result of the progressive shift of the Tramontane influence towards the Mistral influence, with boundary-layer values down to $4-6 \mathrm{~g} \mathrm{~kg}^{-1}$. 
2012101012 UTC

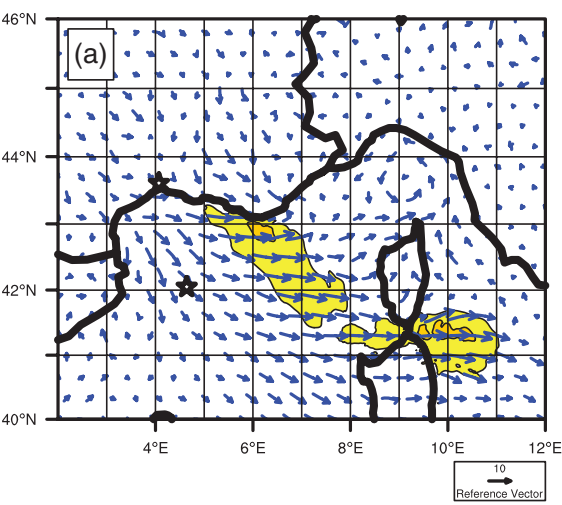

2012101412 UTC

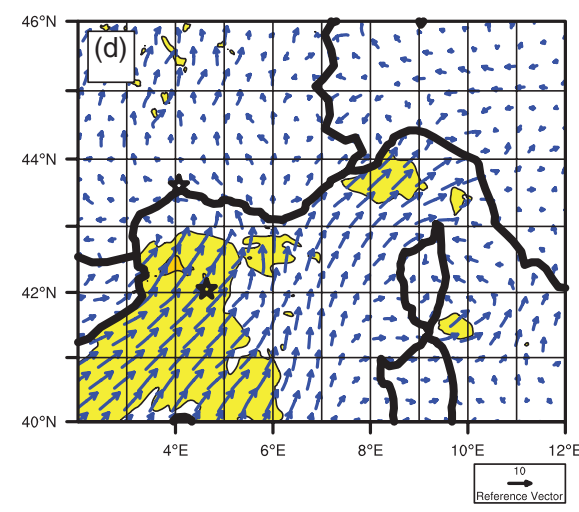

2012101112 UTC

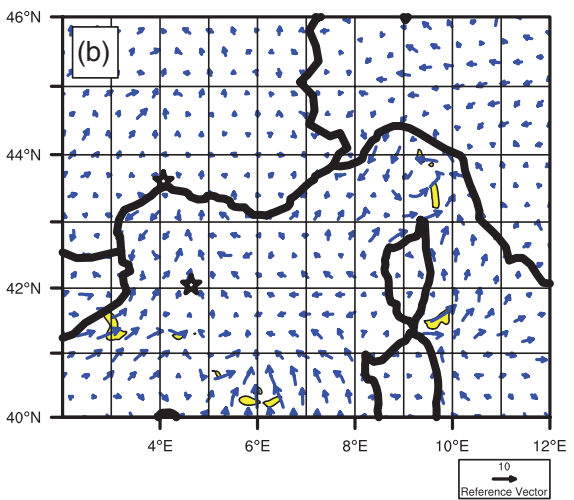

2012101512 UTC

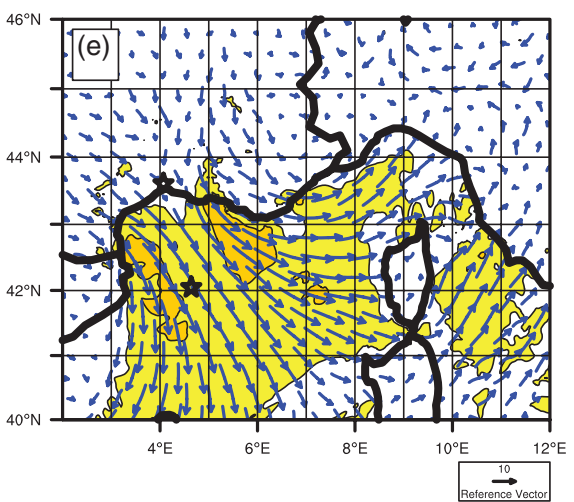

2012101212 UTC

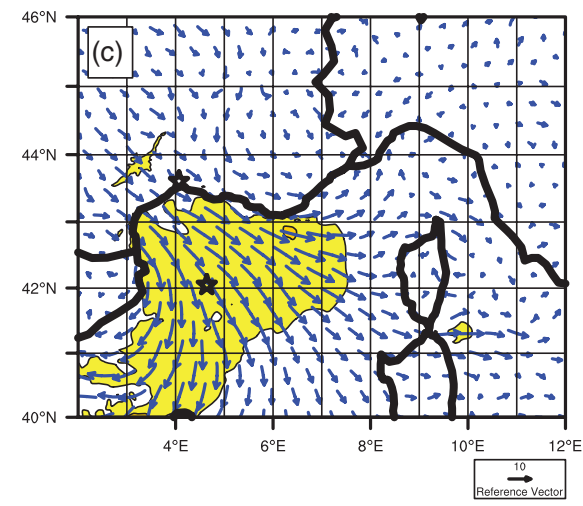

2012101612 UTC

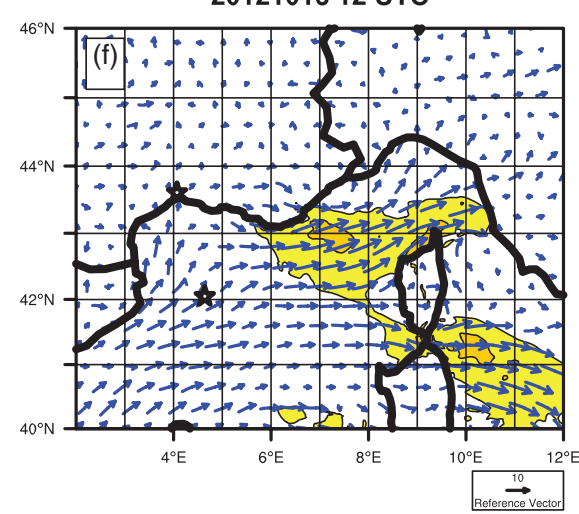

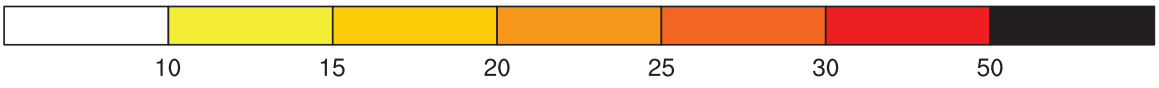

Figure 8. AROME-WMED analyses for $10 \mathrm{~m}$ wind field $\left(\mathrm{m} \mathrm{s}^{-1}\right)$ at 1200 UTC on (a) 10 October, (b) 11 October, (c) 12 October, (d) 14 October, (e) 15 October and (f) 16 October 2012.

Figure 9(c), illustrating wind speed and direction as measured by the UHF wind profiler, reveals the presence of a moderate south/southeasterly flow, starting around 0000 UTC on 11 October 2012, from a previous weak northwesterly flow. The transition from a weak northwesterly flow to a primarily southerly flow had also been studied by Bastin et al. (2006), who reported an event in the same area. The south/southwesterly flow ends around 2100 UTC on 11 October 2012, when the westerly flow is found to take over and progressively become northwesterly. Wind speed values associated with the southwesterly flow are found to not exceed $5 \mathrm{~m} \mathrm{~s}^{-1}$ up to $2 \mathrm{~km}$, while values in excess of $15 \mathrm{~m} \mathrm{~s}^{-1}$ are present in the altitude interval $1-3 \mathrm{~km}$ after 2100 UTC on 11 October 2012, when the westerly flow takes over. Between 0300 UTC and 1200 UTC on 12 October 2012 the depth of the moist layer is comparable to the top of the elevated Tramontane plume $(2.4 \mathrm{~km})$, while it gradually decreases afterwards as the Tramontane is superseded by Mistral. The progressive change of moist to dry air is accompanied by a subsidence of the boundary layer. At 1800 UTC 12 October 2012 strong winds (in excess of $15 \mathrm{~m} \mathrm{~s}^{-1}$ ) extend up to $4 \mathrm{~km}$, possibly as a result of the merging of Tramontane and Mistral in the proximity of Candillargues (see also Saïd etal. (2016)). These results are also confirmed by the observations performed by another UHF wind profiler located in the Rhône valley, east of Candillargues, showing a strong northerly flow starting at 1800 UTC 12 October 2012 (not shown).

Figure 9(a) also reveals the presence of a dry layer most probably intruding from the lower stratosphere as a result of a tropopause-folding event (Di Girolamo et al., 2009a; Russell et al., 2009,2012 ). Evidence of this dry layer is present between $\sim 1800$ UTC 10 October 2012 and $\sim 0600$ UTC 11 October 2012. The dry lamina has a vertical extent of $1-1.5 \mathrm{~km}$ (getting thinner with time) and showing a descending trend from an initial altitude of $4 \mathrm{~km}$ down to approximately $2 \mathrm{~km}$. The lamina is found to descend with an apparent fall speed of $250-270 \mathrm{~m} \mathrm{~h}^{-1}$. The stratospheric origin of the observed dry layer has been verified by the application of a Lagrangian trajectory model (NOAA-ARL HYSPLIT: Draxler and Rolph, 2003). The backward trajectory extending back in time for $240 \mathrm{~h}$ and ending at an altitude of $3 \mathrm{~km}$ and at 1800 UTC 10 October 2012 - this being the height and time the elevated dry layer was first observed - reveals (not shown here) that the air mass observed in Candillargues originated in North America and descended from an altitude of $8-10 \mathrm{~km}$.

Gravity wave activity is observed beneath the dry layer during the stratospheric intrusion event, most probably caused by the subsidence of the intruding heavy dry air or resulting from the upward propagation of wave activity in the nocturnal boundary layer. The propagation of gravity waves is clearly highlighted by the wavy structure of the humidity filaments observed between 2 and $4 \mathrm{~km}$ at the beginning of the measurement period until approximately 0600 UTC 11 October 2012 (Figure 9(a)). Afterwards, as a result of the flow reversal and air-mass change, the effects of wave propagation are no longer observed. Statically stable environments such as the nocturnal boundary layer support gravity wave propagation. In order for internal gravity waves to take place, their wave frequencies must be smaller than the Brunt-Väisälä frequency, or buoyancy frequency, this latter being determinable from the lidar measurements of potential temperature. In the altitude region where waves are observed, Brunt-Väisälä frequencies are found to be smaller than $2 \times 10^{-2} \mathrm{~Hz}$, which correspond to a threshold wave period of $5 \mathrm{~min}$. The effective wave period and amplitude of the gravity wave can be inferred from the wavy shape of the humidity filaments present in the Raman lidar water vapour mixing ratio measurements; these are found to be $50 \mathrm{~min}$ and $250 \mathrm{~m}$, respectively, the former being larger than the above reported Brunt-Väisälä threshold value in the region of wave propagation (Di Girolamo et al., 2009a), this result confirming that internal gravity waves are likely to take place. 

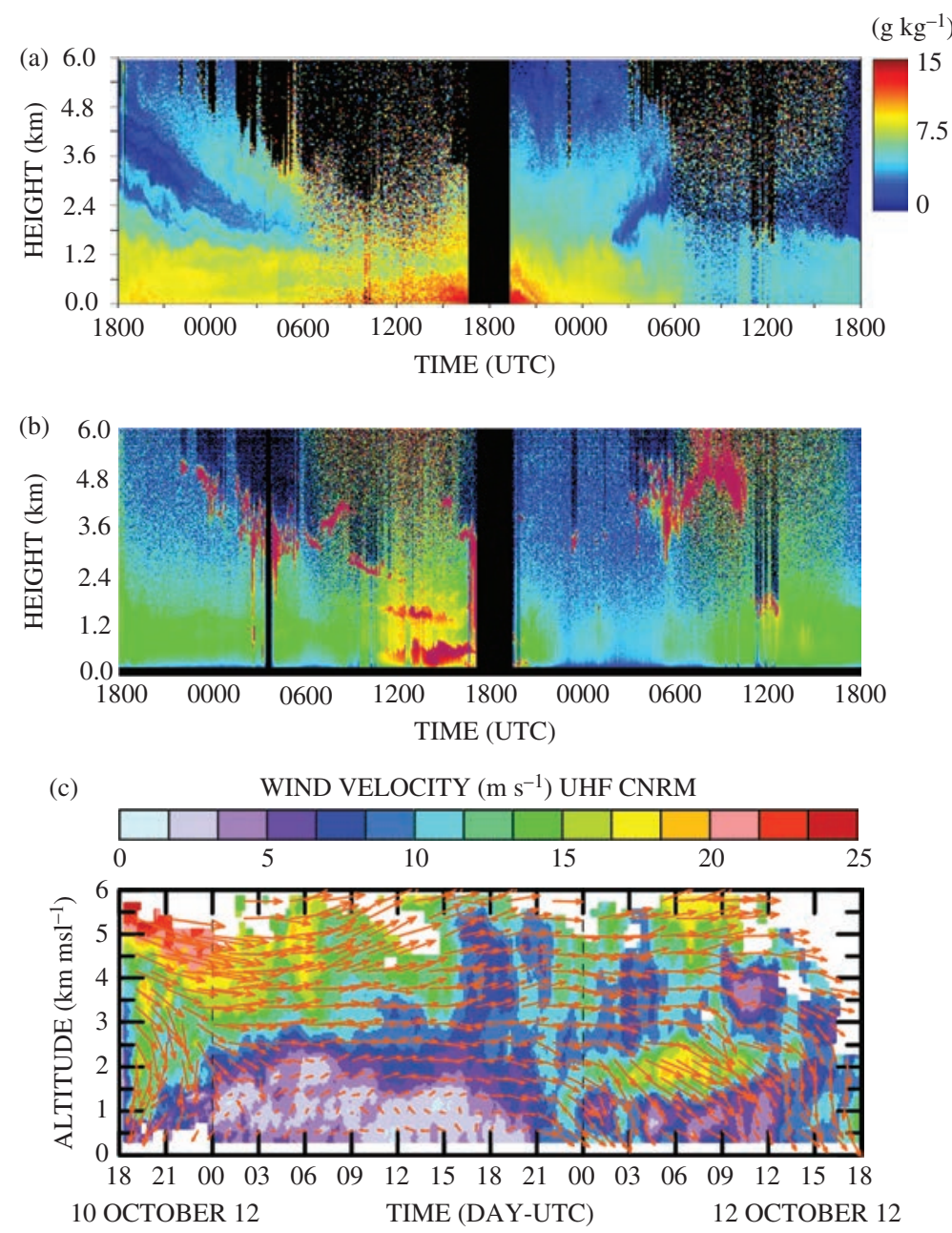

UHF-CNRM CAND (hm,5beams,4kw,375m,15mm,mean:30mn)

Figure 9. Time evolution of (a) the water vapour mixing ratio $\left(\mathrm{g} \mathrm{kg}^{-1}\right)$ and (b) the range-corrected signal at $532 \mathrm{~nm}$ as measured by BASIL, and (c) the wind speed and direction as measured by the UHF wind profiler, over the $48 \mathrm{~h}$ time period from 1800 UTC 10 October to 1800 UTC 12 October 2012 . As the range-corrected signal is expressed in arbitrary units no colour legend was introduced for this quantity as the colour legend for water vapour mixing ratio can be used to identify its relative changes.

The range-corrected signal at $532 \mathrm{~nm}$ (Figure $9(\mathrm{~b}))$ reveals a significant change in particle backscatter $(30-40 \%$, similar to that observed in Figure 4(b)) caused by the arrival of the more humid aerosol-laden air advected by the southerly marine flow, replacing the colder and drier air transported by the Mistral. The increase in the range-corrected signal may also be partially ascribable to aerosol swelling and changes in its optical properties as a result of humidification. The figure also shows the presence of midlevel clouds progressively descending from 5 to $2 \mathrm{~km}$ during the first half of the measurement session. The occurrence of virgae is also testified by the presence of narrow almost vertical dark red lines below the cloud base (0330-0500 UTC 11 October 2012).

Figure 10(a) and (b) illustrate the integrated water vapour (IWV) and $10 \mathrm{~m}$ winds from the 0000 and 0600 UTC AROMEWMED analyses on 12 October 2012. The IWV analyses at 0000 UTC indicates the presence of moist air over the eastern part of the domain associated with the residual southerly marine flow, while at 0600 UTC the arrival of drier air over the northwestern Mediterranean is clearly visible. These results are also in good agreement with the water vapour measurements performed by BASIL (Figure 9(a)), which reveal a limited variability of the water vapour mixing ratio within the lowest $500 \mathrm{~m}$, with values in the range $7-9 \mathrm{~g} \mathrm{~kg}^{-1}$.

Figure 11 illustrates the time evolution of the water vapour mixing ratio as simulated by AROME-WMED and Meso-NH over the same time period considered in Figure 9. Both Meso$\mathrm{NH}$ and AROME-WMED properly simulate the arrival of the humid air in the boundary layer, with a correct timing and with very similar mixing ratio values (up to $14-15 \mathrm{~g} \mathrm{~kg}^{-1}$ ). In this case-study, the two models seem to slightly underestimate the depth of the moist layer and, ultimately, the boundary-layer height, with AROME-WMED being in better agreement with BASIL (moist layer extending up to approximately $1200 \mathrm{~m}$ for the model and up to approximately $1500 \mathrm{~m}$ for BASIL) than Meso-NH (moist layer extending up to approximately $900 \mathrm{~m}$ ). The two models only partially simulate the deep penetration into the troposphere of the dry intruding layer, with AROME-WMED performing slightly better than MESO-NH, but this still appears to be a limitation of mesoscale modelling (Di Girolamo et al., 2009a). The abrupt change at 2100 UTC 11 October 2012 in the AROME-WMED moisture content is associated with the forecast over Candillargues of a precipitating system from 1800 UTC to 2100 UTC associated with high water vapour mixing ratio in the low levels, followed by drier air after the passage of the system.

Values of the mean absolute and relative bias of AROMEWMED vs. BASIL (not shown) are smaller than $0.5 \mathrm{~g} \mathrm{~kg}^{-1}$ and $5 \%$, respectively, while values of the mean absolute and relative bias of Meso-NH vs. BASIL (not shown) are always smaller than $0.8 \mathrm{~g} \mathrm{~kg}^{-1}$ and $10 \%$, respectively. As for the previous case-study, the bias of Meso-NH vs. BASIL seems to be larger than the bias of AROME-WMED vs. BASIL. Furthermore, values of the mean relative bias for this case-study are much smaller than those found on 19/20 September (which were exceeding 100\%) as a result of the much larger mixing ratio values $\left(5-7 \mathrm{~g} \mathrm{~kg}^{-1}\right)$ on this day above the boundary-layer top and up to $4.5 \mathrm{~km}$ for both BASIL and the mesoscale models. 
2012101200 UTC

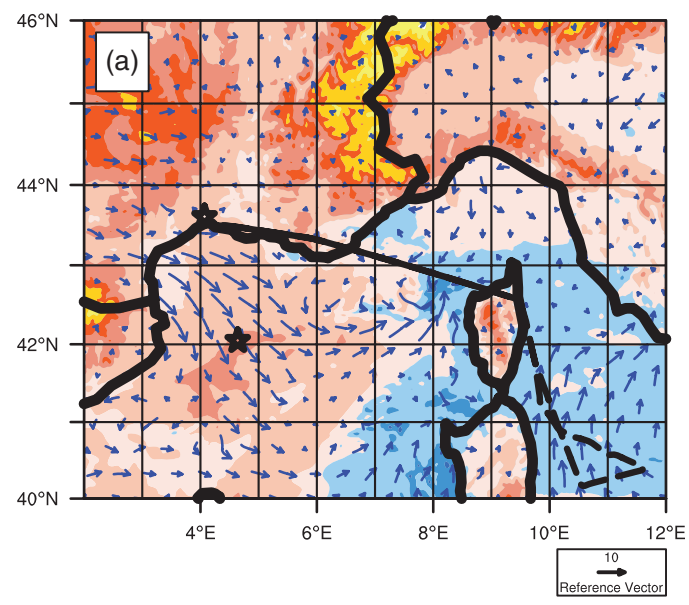

2012101206 UTC

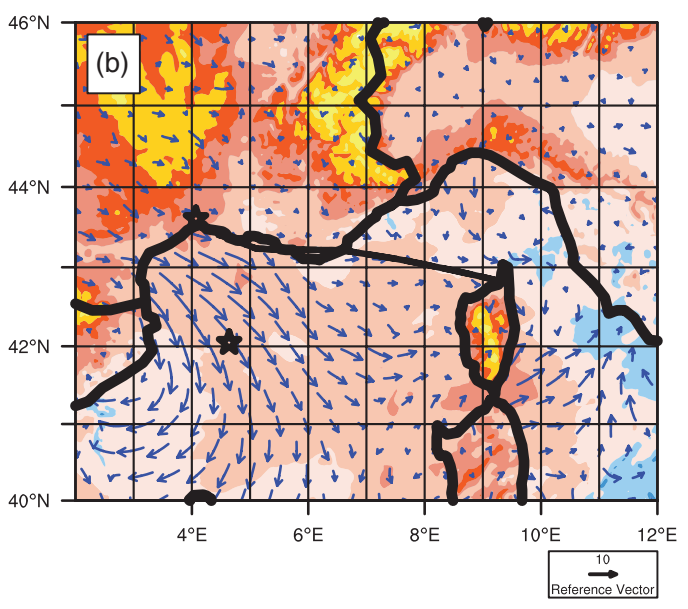

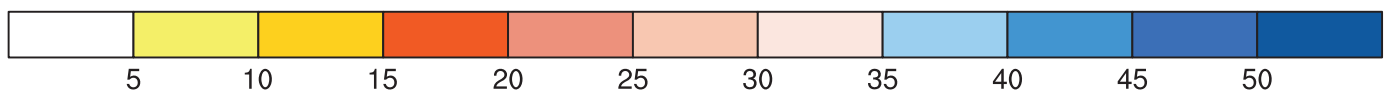

Figure 10. AROME-WMED analysis for IWV $\left(\mathrm{kg} \mathrm{m}^{-2}\right)$ and $10 \mathrm{~m}$ wind speed and direction at (a) 0000 UTC and (b) 0600 UTC 12 October 2012 . ATR42 flight tracks on 12 October 2012 are also included in the figure: the pattern of flight AS44 (0110-0422 UTC with the solid line corresponding to 0110-0210 UTC) in (a), the pattern of flight AS45 (0543-0705 UTC) in (b).

(a)

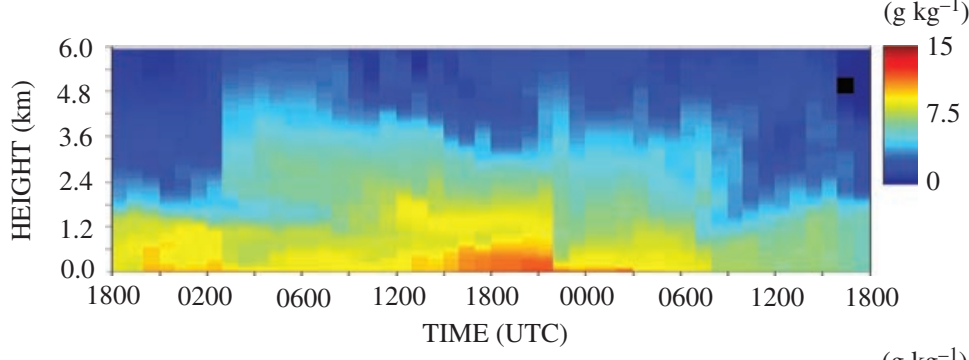

(b)

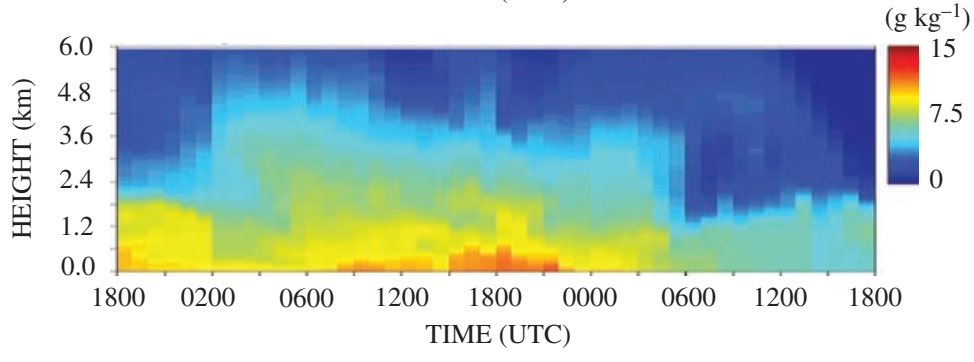

Figure 11. Time evolution of the water vapour mixing ratio as simulated by the mesoscale models (a) AROME-WMED and (b) Meso-NH, over the $48 \mathrm{~h}$ time period from 1800 UTC 10 October to 1800 UTC 12 October 2012.

The ATR 42 performed three flights on 12 October 2012, two of which consisted of transit flights between Montpellier and Bastia partly over the Gulf of Genoa (flight AS44, covering the time interval 0110-0422 UTC, and flight AS45, covering the time interval 0543-0705 UTC, with flight tracks shown in Figure 10(a) and (b), respectively). Figure 12 shows LEANDRE 2 water vapour mixing ratio data (longitude-height cross-sections, i.e. longitude on the $x$-axis and height on the $y$-axis) for the outbound flight AS44 on 12 October 2012 (0110-0210 UTC) and for the inbound flight AS45 on this same day (0543-0705 UTC). Water vapour mixing ratio profiles from LEANDRE 2 for the inbound flight reveal the presence of a humid layer extending up to approximately $2 \mathrm{~km}$ and then progressively getting thinner down to a vertical extent of $\sim 1 \mathrm{~km}$. The layer has mixing ratio values in the proximity of the surface around $7-8 \mathrm{~g} \mathrm{~kg}^{-1}$ and values in the upper portion of the layer about $4-5 \mathrm{~g} \mathrm{~kg}^{-1}$. This thinning humid layer captured by LEANDRE 2 is probably the effect of the arrival of the Mistral flow.

Overpasses in the proximity of Candillargues took place shortly after take-off and before landing in time intervals 0110-0118 UTC and 0650-0705 UTC. The good agreement between the two lidars is clearly revealed by the profile-to-profile comparison in Figure 13(a) and (b). For the former comparison, the considered time interval is after the humidity field reversal associated with the transition from southerly marine flow to northwesterly Tramontane flow, which is well captured by both BASIL and LEANDRE 2. Deviations between BASIL and LEANDRE2 do not exceed $25 \%$ at any height. In this respect, it is to be noticed that, because of air-traffic restrictions and lidar operation startup time, the closest LEANDRE2 profiles to Candillargues are typically about $30 \mathrm{~km}$ eastward. So the deviations observed in Figure 13(a) and (c) in the lower portion of the boundary layer are likely due to the different air masses sounded.

Figure 12 also illustrates the time evolution of the water vapour mixing ratio as simulated by Meso-NH and AROMEWMED along the ATR42 tracks for flight AS44 and AS45. Model simulations indicate a good capability of both AROME-WMED and Meso-NH to reconstruct the humidity field observed by LEANDRE2, both in terms of timing and amplitude, properly reproducing, for example, the humid air uplift along the mountain ridges (Figure $12(\mathrm{a}, \mathrm{b}, \mathrm{e}, \mathrm{f})$ ). The water vapour variability associated with the subsiding dry layers is particularly well described by AROME-WMED (Figure 12(f)).

\subsection{Case-study on 13-15 October 2012}

During the period 9-17 October 2012 additional flow transitions are found to take place over southern France, besides 
(a)

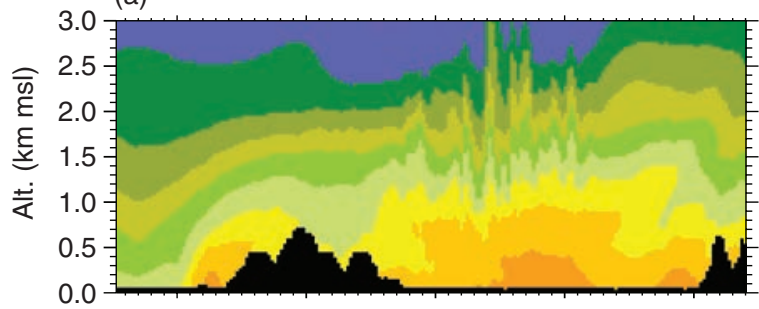

(c)

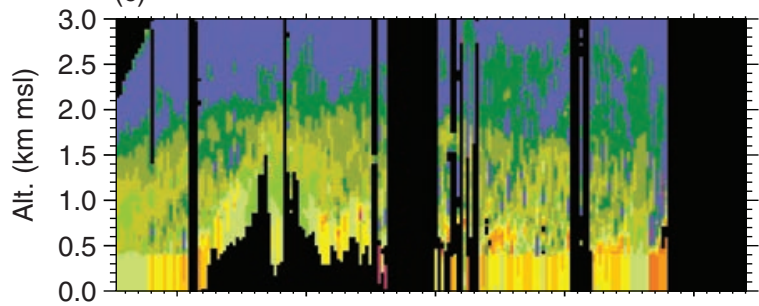

(e) (b)

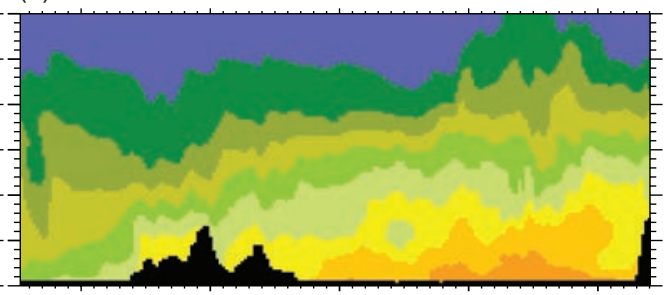

(e)

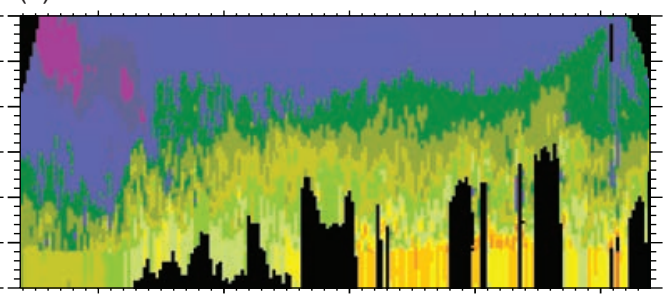

(f)
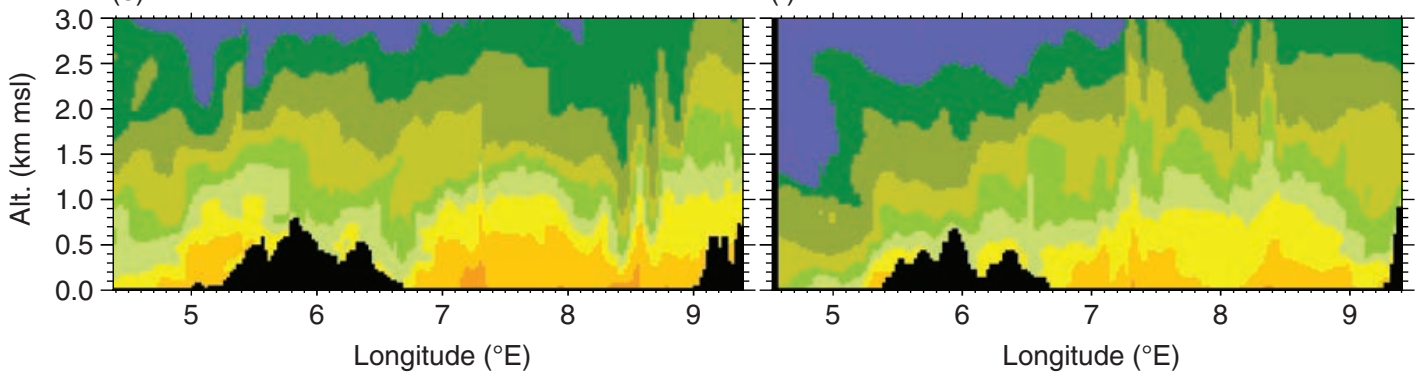

$0 \quad 5 \quad 10 \quad 15$

Figure 12. LEANDRE 2 water vapour mixing ratio data (c) for flight AS44 (0110-0210 UTC) and (d) for flight AS45 (0543-0705 UTC), on 12 October 2012 . The figure also illustrates the (a,b) Meso-NH and (e,f) AROME-WMED forecasts for the same time and longitude intervals. The black vertical lines are missing data. The orography also appears in black.
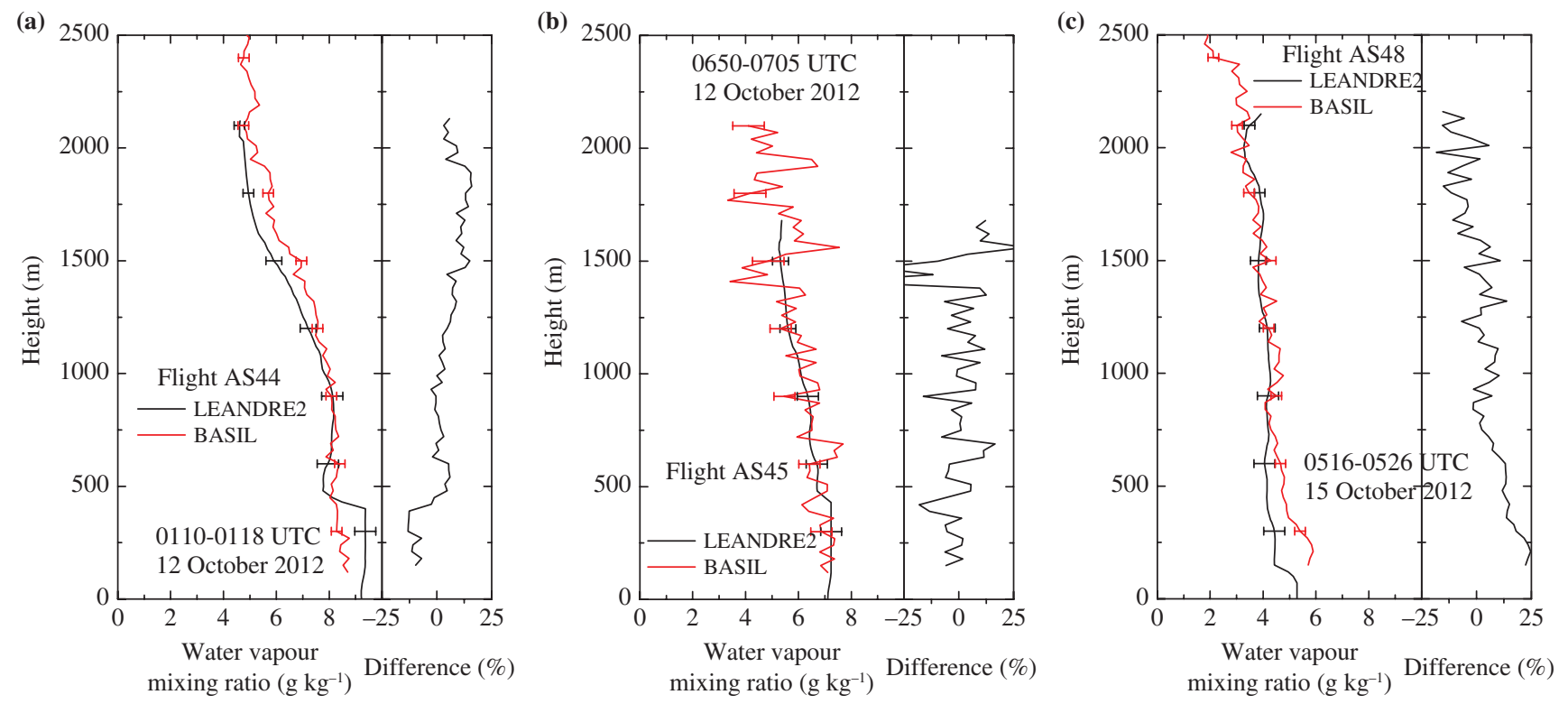

Figure 13. Profile-to-profile comparison between BASIL and LEANDRE 2 for the time intervals: (a) 0110-0118 UTC 12 October, (b) 0650-0705 UTC 12 October, and (c) 0516-0526 UTC 15 October 2012.

those described and discussed in section 6.1. Specifically, a northwesterly/northeasterly $\left(330-30^{\circ}\right)$ flow below westerlies is observed between 0000 and 0600 UTC on 14 October 2012. A progressive transition to southeasterly $\left(120^{\circ}\right)$ flow is found to take place between 0600 and 1500 UTC on 14 October 2012, capped by westerlies (see wind profiler data in Figure 14(c)), while at 1500 UTC 14 October 2012 the onset of the northwesterly Tramontane $\left(320^{\circ}\right)$ flow is observed, accompanied by a strengthening of the wind. The $10 \mathrm{~m}$ wind fields from AROME-WMED 3hourly analyses (Figure 8) reveal that at 1200 UTC 14 October
2012 a southwesterly marine flow is present all over the northwestern Mediteranean Sea, at 1200 UTC 15 October 2012 the northwesterly Tramontane/Mistral flow appears to be again well established, and at 1200 UTC 16 October 2012 a southwesterly marine flow is again present over the Gulf of Lion.

Figure 14(a) illustrates the time evolution of the water vapour mixing ratio as measured by BASIL over a time period of approximately $32 \mathrm{~h}$ from 2200 UTC 13 October 2012 to 0600 UTC 15 October 2012. A moderate cold front extends from southern Portugal towards central France and Germany. Ahead of the front 

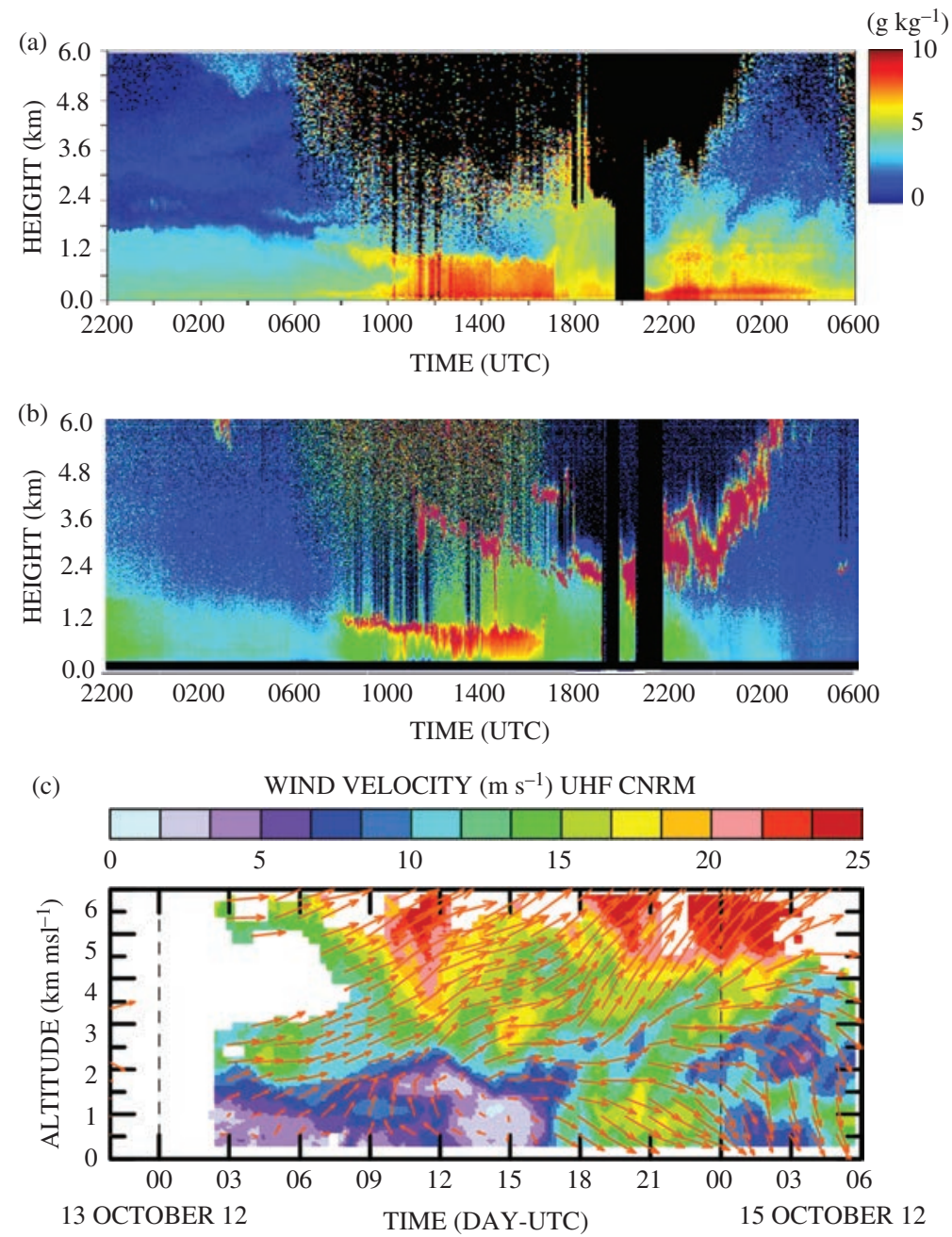

UHF-CNRM CAND (hm,5beams,4kW,375m,15mn,mean:30mn)

Figure 14. Time evolution of (a) the water vapour mixing ratio and (b) the range-corrected signal at $532 \mathrm{~nm}$ as measured by BASIL, and (c) the wind speed and direction as measured by the UHF wind profiler, over the $32 \mathrm{~h}$ time period from 2200 UTC 13 October to 0600 UTC 15 October 2012 . As the range-corrected signal is expressed in arbitrary units no colour legend was introduced for this quantity as the colour legend for water vapour mixing ratio can be used to identify its relative changes.

the flow rapidly becomes southwesterly and cyclonic at all levels. The figure reveals the arrival of the moist air in Candillargues starting at approximately 0600-0800 UTC on 14 October 2012, which is brought by the southwesterly flow, following the low-level wind reversal from a previous northwesterly flow. An anvilshaped moist layer is observed at the top of the boundary layer starting at 0800 UTC, which may be evidence of the presence of either a low-level outflow or a vertical shear in the wind direction leading to differential advection of humidity at different levels. The edge of the outflow boundary or a vertical shear can be detected by Raman lidars, especially in clear air, with signatures in both water vapour and particle backscatter. Convergence occurs along the leading edge of the downdraught. Convergence of dust and aerosols at the leading edge is responsible for the particle backscatter signature in Figure 14(b). The anvil-shaped moist layer is also well visible in Meso-NH simulation (Figure 16(b)). The moistening of the air masses over Candillargues is observed until the northwesterly Tramontane flow sets in and starts bringing drier air after 1630 UTC 14 October 2012. Data from the UHF wind profiler (Figure 14(c)) reveal the presence of a moderate southwesterly marine flow starting on 13 October 2012 (visible in the figure after 0300 UTC 14 October 2012) and the onset of the northwesterly Tramontane flow around 1630 UTC 14 October 2012. Wind speeds during the southwesterly marine flow do not exceed $5 \mathrm{~m} \mathrm{~s}^{-1}$ up to $2 \mathrm{~km}$, while they grow exceeding $15 \mathrm{~m} \mathrm{~s}^{-1}$ as soon as the Tramontane takes over after 1630 UTC 14 October 2012. It is to be noticed that an increase of low-level humidity is observed at 2100 UTC 14 October 2012, while a northwesterly wind is blowing. This is associated with the passage of the cold front, as in fact during the second half of the day on 14 October 2012 an upper low, resulting from a wide trough shifting over Spain, deepens over France. As a result, the upper-level flow becomes southwesterly and consequently a low-level warm, moist air axis builds from the Balearic Islands to the Gulf of Lion (clearly highlighted by the $950 \mathrm{hPa}$ wind field analysis at 1800 UTC 14 October 2012, not shown here). Lidar measurements were stopped between 1930 and 2100 UTC due to rain, which (together with virga observed until 0200 UTC 15 October 2012) contributed to the air moistening observed after 2100 UTC. The humidity values close to the surface start decreasing after the frontal passage, the decrease being reinforced by the shift from Tramontane to Mistral within the boundary layer after 0200 UTC.

Water vapour mixing ratio values within the boundary layer are found to change from values of $3-4 \mathrm{~g} \mathrm{~kg}^{-1}$ associated with the northwesterly Tramontane flow to values of $8-10 \mathrm{~g} \mathrm{~kg}^{-1}$ due to the arrival of the humid southeasterly marine flow, and decrease again down to $3-6 \mathrm{~g} \mathrm{~kg}^{-1}$ with the subsequent Tramontane flow onset, followed by the Mistral onset. In this case, the water vapour decrease associated with Tramontane onset is less marked than in the 10-12 October case-study (section 6.1). The increase in water vapour mixing ratio associated with the arrival of southeasterly marine flow is marked, with water vapour mixing ratio values in the central portion of the boundary layer (around $0.6 \mathrm{~km}$ ) increasing by a factor of approximately 2 from $\sim 4$ to $\sim 9 \mathrm{~g} \mathrm{~kg}^{-1}$ in the time interval 1000-1100 UTC 14 October 2012 (i.e. $\left.5 \mathrm{~g} \mathrm{~kg}^{-1} \mathrm{~h}^{-1}\right)$. However, also in this case a less marked increase in 
2012101506 UTC

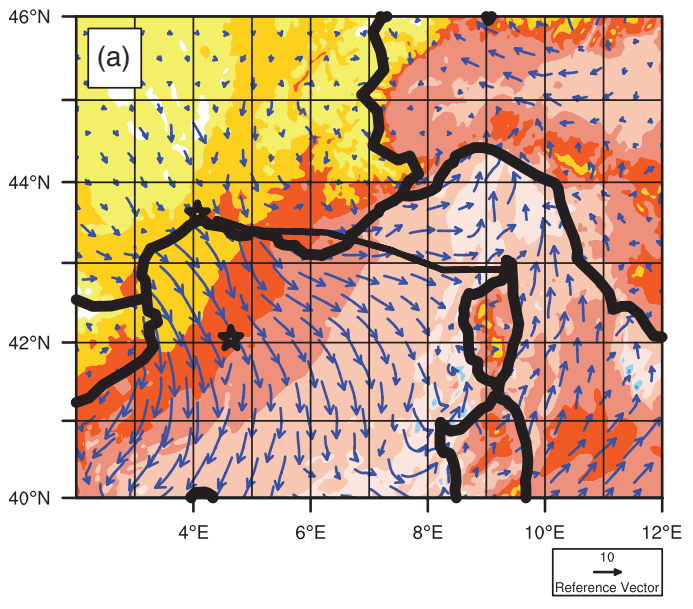

2012101512 UTC

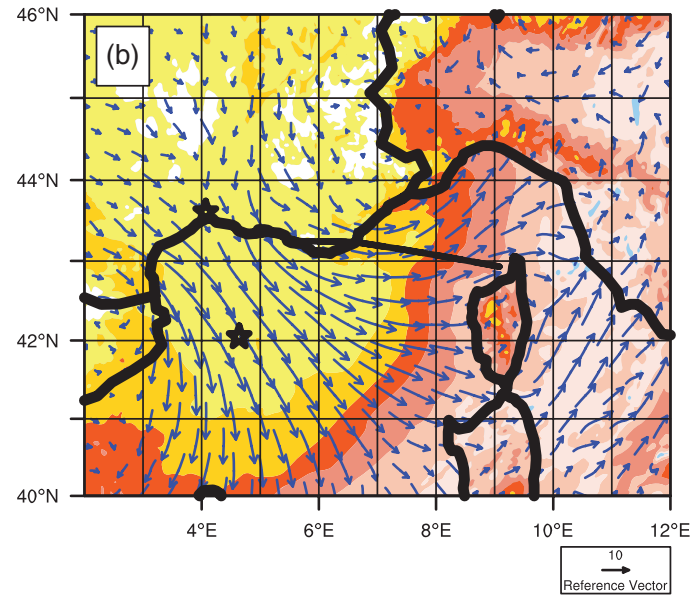

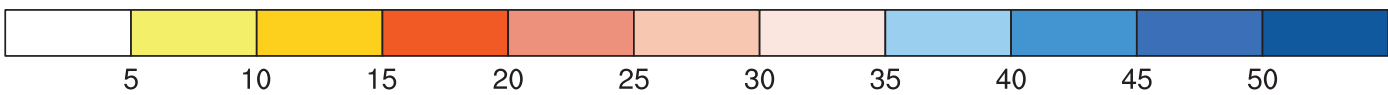

Figure 15. AROME-WMED analysis for IWV $\left(\mathrm{kg} \mathrm{m}^{-2}\right.$ ) and $10 \mathrm{~m}$ wind speed and direction at (a) 0600 UTC and (b) 1200 UTC 15 October 2012 . ATR42 flight tracks on 15 October 2012 are also included in the figure: the pattern of flight AS48 (0516-0633 UTC) in (a), the pattern of flight AS50 (1225-1349 UTC) in (b).

(a)

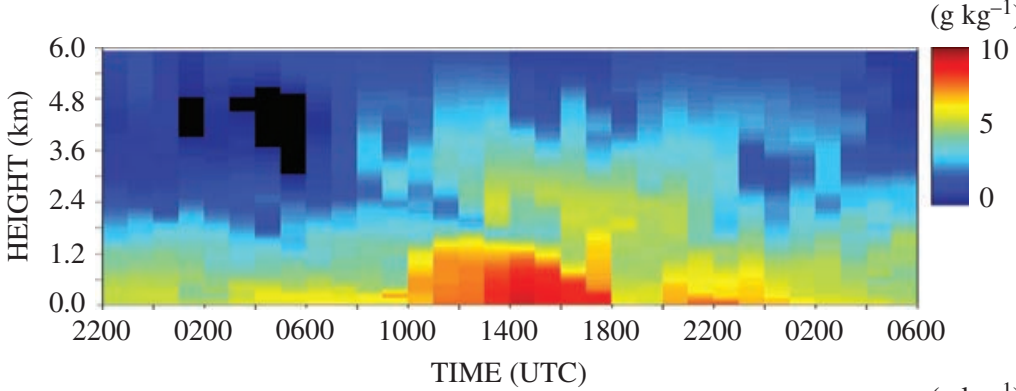

(b)

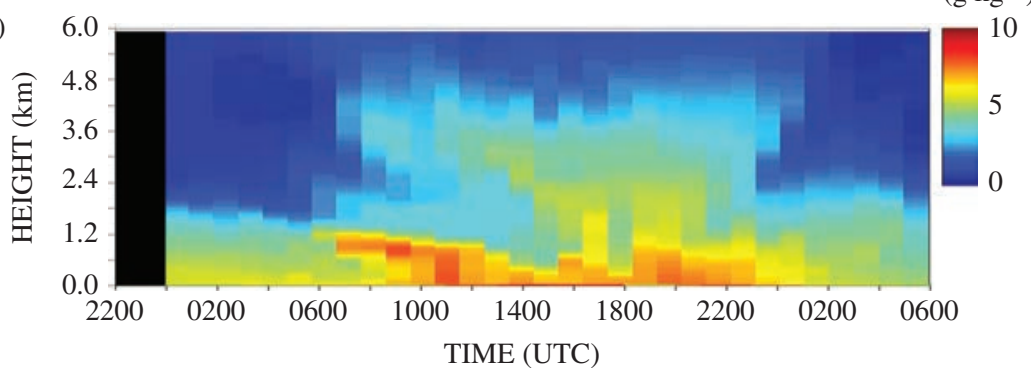

Figure 16. Time evolution of the water vapour mixing ratio as simulated by the mesoscale models (a) AROME-WMED and (b) Meso-NH, over the period from 2200 UTC 13 October to 0600 UTC 15 October 2012

water vapour mixing ratio is observed within the boundary layer with respect to the case-study on 19/20 September 2012, as a result of the presence of the southwesterly flow ahead of the cold front, again not accompanied by the presence of a sea-breeze flow.

The particle backscatter, and consequently the aerosol load, is found to increase by approximately $50 \%$ with the arrival of the humid air associated with the onset of the southwesterly marine flow (Figure 14(b)). Clouds at the top of the boundary layer are found to form starting at $\sim 0800$ UTC on 14 October 2012 with the arrival of the southwesterly marine flow. The IWV fields from the AROME-WMED analyses at 0600 (Figure 15(a)) and 1200 UTC (Figure 15(b)) on 15 October 2012 highlight the progression of the dry air associated with Tramontane and Mistral over the Gulf of Lion, with Tramontane at the western edge and Mistral at the eastern edge, in good agreement with the evolution of the water vapour field measured by BASIL, while the $10 \mathrm{~m}$ wind field reveals the intensification of the Mistral flow, in good agreement with the measurements from the UHF wind profiler. The strengthening of the Mistral in the Rhône valley is due to the deepening of the low in the Gulf of Genoa. This strengthening is also confirmed by the increase of the northerlies and westerlies observed by the UHF wind profilers in Marignane (east of Candillargues, $43^{\circ} 25^{\prime} \mathrm{N}, 5^{\circ} 13^{\prime} \mathrm{E}$ ) and in Levant (further east of Candillargues, $43^{\circ} 03^{\prime} \mathrm{N}, 6^{\circ} 28^{\prime} \mathrm{E}$ ), respectively (not shown). Consequently, the northeastern edge of the Mistral spreads as far as the entrance of the Gulf of Genoa.

Both Meso-NH and AROME-WMED (Figure 16) properly simulate the arrival of the anvil-shaped humid layer in the boundary layer associated with the southwesterly marine flow, with a correct timing and comparable mixing ratio values (up to $8-9 \mathrm{~g} \mathrm{~kg}^{-1}$ ). Also in this case-study, the depth of the moist layer seems to be slightly different for the two models, with the estimate by Meso-NH being in better agreement with BASIL (moist layer extending for both up to approximately $1200 \mathrm{~m}$ ) than with AROME-WMED (moist layer extending up to approximately $1500 \mathrm{~m}$ ). The development on 14 October 2012 of a slightly shallower PBL with respect to the previous case-studies (19/20 September 2012 and 10-12 October 2012) is associated with the presence of high-level clouds $(7-10 \mathrm{~km})$ during the early phase of the day (starting at 0700 UTC), which partially shaded the Sun and reduced surface heating, thereby limiting the development of the convective boundary layer. On the other hand, AROME-WMED forecasts better describe the abrupt decrease in water vapour content around 1700-1800 UTC 14 October 2012 with the onset 
(a)

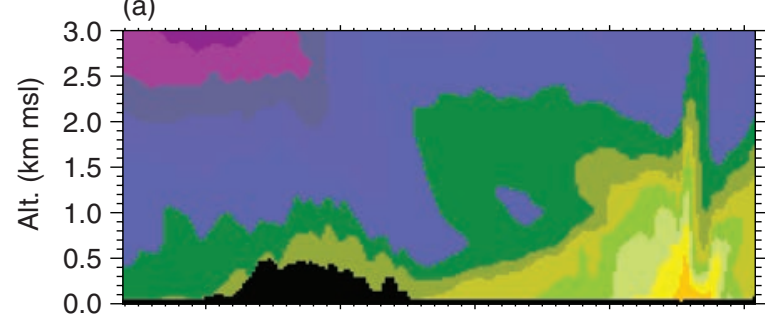

(c)

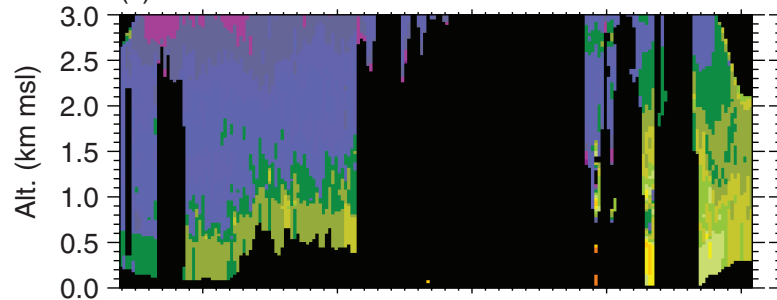

(e)

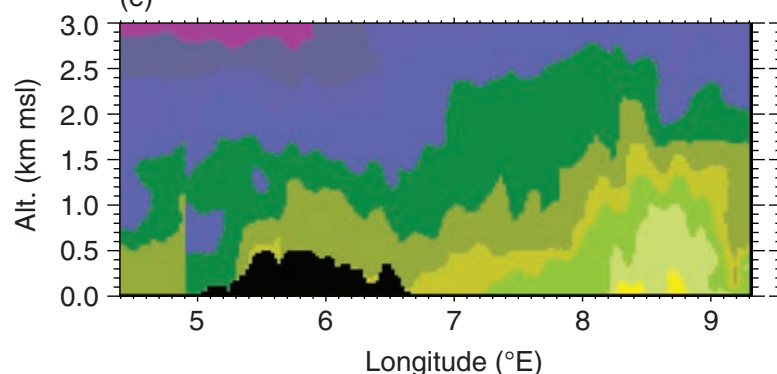

(b)

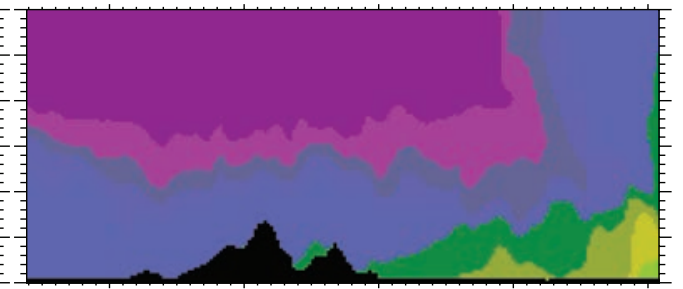

(e)

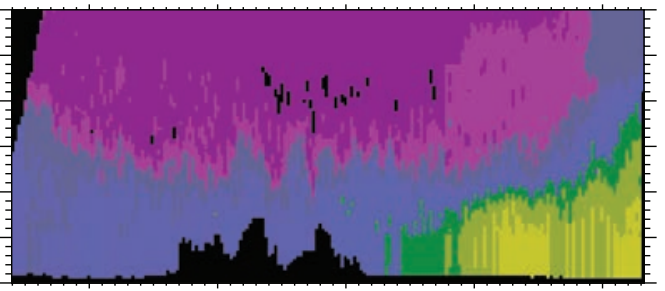

(f)

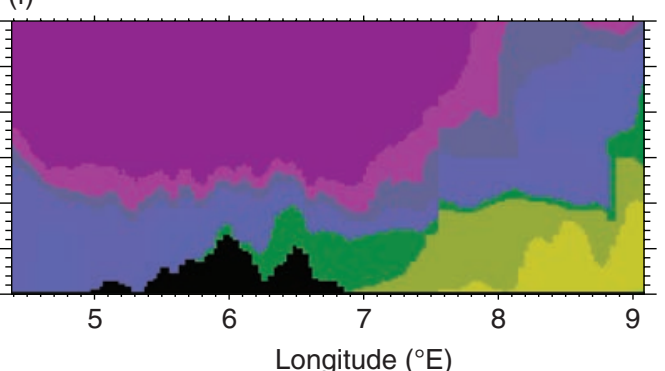

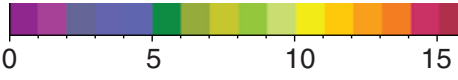

Figure 17. LEANDRE 2 water vapour mixing ratio data $\left(\mathrm{g} \mathrm{kg}^{-1}\right)$ for (c) flight AS48 (0516-0633 UTC) and (d) flight AS50 (1225-1349 UTC), on 15 October 2012. The figure also illustrates the (a,b) Meso-NH and (e,f) AROME-WMED forecasts for the same time and longitude intervals. The black vertical lines are missing data. The orography also appears in black.

of the northwesterly Tramontane winds. Both models well capture the elevated humid layer which is present in the free troposphere, extending from $\sim 2$ to $\sim 4 \mathrm{~km}$, in the time interval $0700-2300$ UTC 14 October 2012, which is also visible in BASIL data. Values of the mean absolute and relative bias of AROME-WMED vs. BASIL (not shown) remain smaller than $2.0 \mathrm{~g} \mathrm{~kg}^{-1}$ and $20 \%$, respectively, while values of the mean absolute and relative bias of Meso-NH vs. BASIL (not shown) are smaller than $2.5 \mathrm{~g} \mathrm{~kg}^{-1}$ and $30 \%$, respectively.

On 15 October 2012 the ATR42 made two flights (AS48 and AS50) over the Gulf of Lion; the flight tracks, shown in Figure 15, were similar to those of the inbound flight on 12 October 2012. The outbound flight was conducted across a cold front ahead of the Mistral, while the inbound flight was conducted in Mistral conditions, the cold front having moved east of Corsica at the time. Figure 17 shows LEANDRE 2 water vapour mixing ratio data (longitude-height cross-sections) for flight AS48 on 15 October 2012, covering the time interval 0516-0633 UTC, and for flight AS50 on this same day, covering the time interval 1225-1349 UTC.

Water vapour mixing ratio profiles from LEANDRE 2 during the initial portion of the outbound flight reveal the presence of a low-humidity layer extending up to approximately $2 \mathrm{~km}$, with mixing ratio values in the proximity of the surface around $5-6 \mathrm{~g} \mathrm{~kg}^{-1}$, which corresponds to the dry period in the presence of the Tramontane flow, the low-humidity layer being also observed by BASIL during the same time interval (Figure 14(a)). The profile-to-profile comparison between the two lidars for the time interval from 0516 to 0526 UTC (Figure 12(c)), again representing the dry period in the presence of the tramontane flow, reveals the good agreement between LEANDRE 2 and BASIL, both systems showing the presence of the humid layer extending up to approximately $2 \mathrm{~km}$. Later on, during the inbound flight, LEANDRE 2 data document the northeastern edge of the
Mistral plume, with a well-mixed boundary layer extending up to approximately $1.5 \mathrm{~km}$ (between 4 and $5^{\circ} \mathrm{E}$ ).

Figure 17 also illustrates the time evolution of the water vapour mixing ratio as simulated by Meso-NH and AROME-WMED along the ATR42 tracks for flight AS48 and AS50, respectively. Also for this case-study, model simulations indicate a good capability of both AROME-WMED and Meso-NH to reproduce the humidity field evolution observed by LEANDRE2, properly simulating the time-height variability of the humidity field. For example, both models properly reproduce the humid air uplift along the mountain ridges $(\mathrm{a}, \mathrm{b}, \mathrm{e}, \mathrm{f})$, the subsiding of the dry layers over the sea $(b, f)$ and the progressive thickening of the surface humid layer observed during the eastern part of both flights.

\section{Model sensitivity experiments}

To get deeper insight into some of the specific phenomena and results discussed above, several sensitivity studies were carried out with Meso-NH. The first one was aimed at getting a better assessment of the potential role of the sea breeze in the case-study of 19/20 September 2012. For this purpose the contribution of thermally induced circulations to the observed low-level wind reversal was quantified based on the use of Meso-NH forecasts, with and without the radiation scheme switched on. In fact, switching off the radiation scheme precludes the development of upslope flow and sea breeze. Figure 18 illustrates the results of this sensitivity experiment, which was carried out for the three case-studies discussed in this article. The left panels illustrate the difference in the $2 \mathrm{~m}$ water vapour mixing ratio between the reference forecast and the no-radiation forecast, while the right panels illustrate the $10 \mathrm{~m}$ wind vectors for the reference forecast and for the no-radiation forecast. Results reveal that, although all three case-studies are to some extent impacted by thermal circulations, only the first one (19/20 September 2012) 

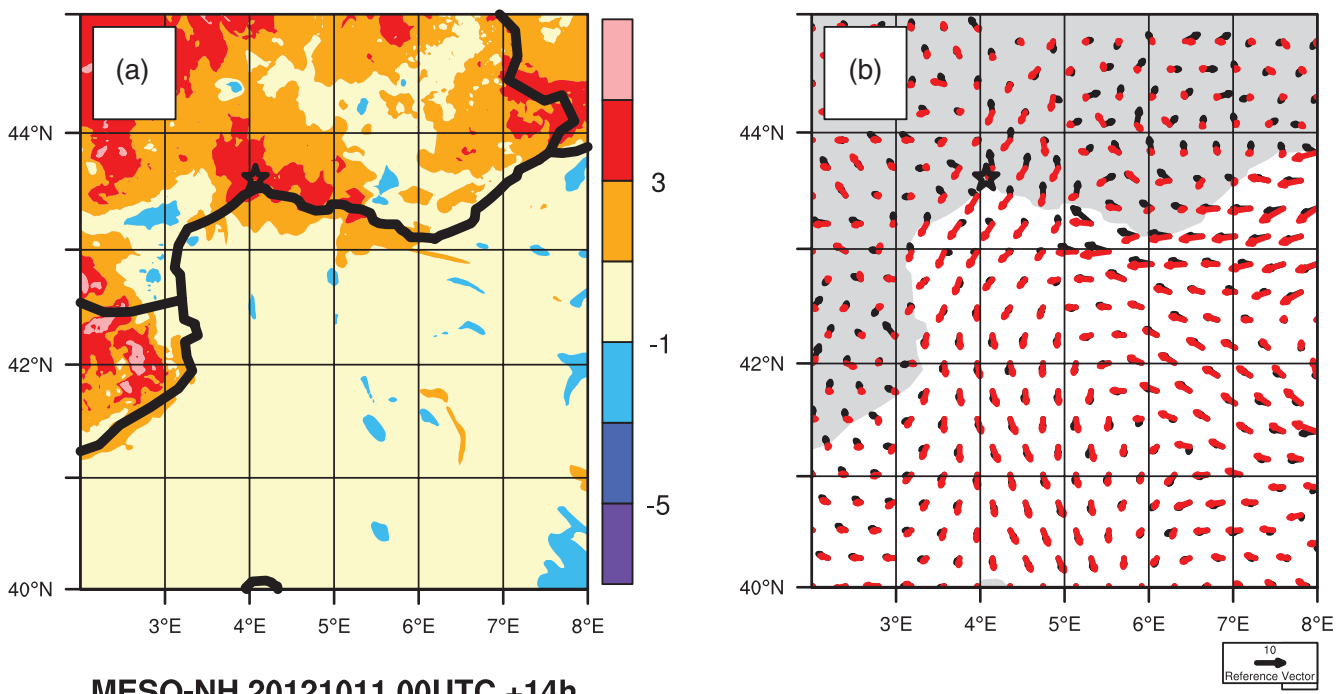

MESO-NH 20121011 00UTC $+14 \mathrm{~h}$
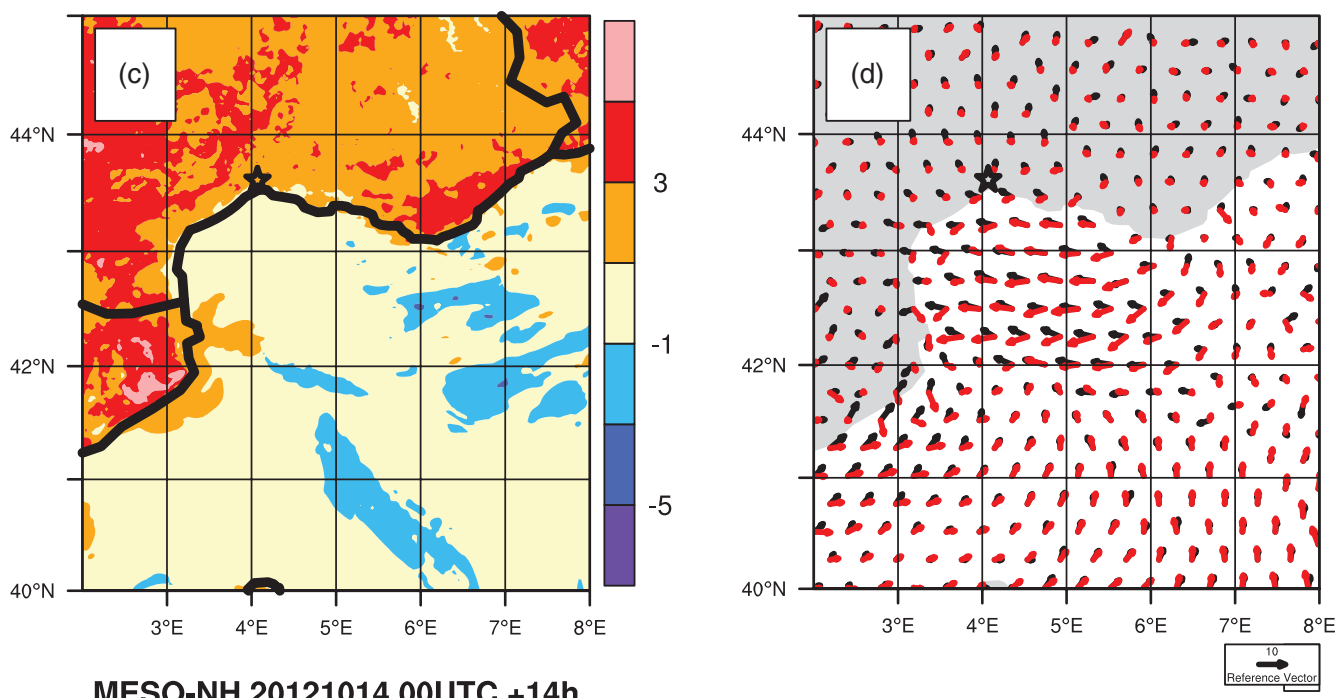

MESO-NH 20121014 00UTC $+14 \mathrm{~h}$
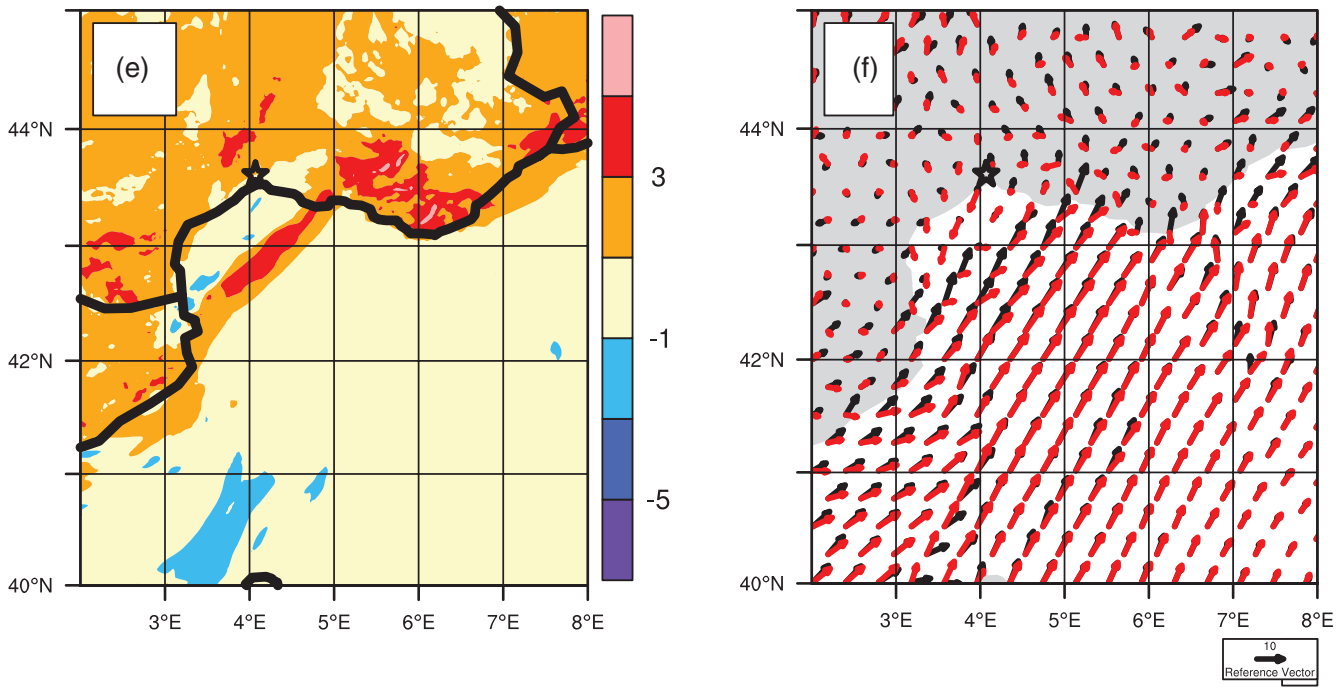

Figure 18. Impact of thermally driven circulations on Meso-NH forecasts for the three case-studies: $(\mathrm{a}, \mathrm{c}, \mathrm{e})$ difference in the $2 \mathrm{~m}$ water vapour mixing ratio ( $\mathrm{g} \mathrm{kg}^{-1}$ ) between the reference forecast and the no-radiation forecast, and (b,d,f) $10 \mathrm{~m}$ wind vectors for the reference forecast (in black) and for the no-radiation forecast (in red).

shows a strong contribution of the sea breeze in the vicinity of Candillargues. Specifically, at 1400 UTC 20 September 2012 the wind vectors in the reference forecast indicate a southeasterly flow, while in the no-radiation forecast the flow is from northeast (almost completely reversed). A less marked wind direction change is present at 1400 UTC on both 11 October 2012 and 14 October 2012, with the flow being almost southeasterly with and without switching on the radiation scheme. Additionally, the difference in the $2 \mathrm{~m}$ water vapour mixing ratio is $3-5 \mathrm{~g} \mathrm{~kg}^{-1}$ at 1400 UTC 20 September 2012, while it is $1-3 \mathrm{~g} \mathrm{~kg}^{-1}$ at 1400 UTC 11 October 2012 and even less $\left(<1 \mathrm{~g} \mathrm{~kg}^{-1}\right)$ at 1400 UTC 14 October 2012. These results fully support our hypothesis that the role of thermally driven circulation is much more important in the first case-study than in the other two and, consequently, a strong contribution of the sea breeze in the vicinity of Candillargues is present only in this first case-study, determining a southeasterly 

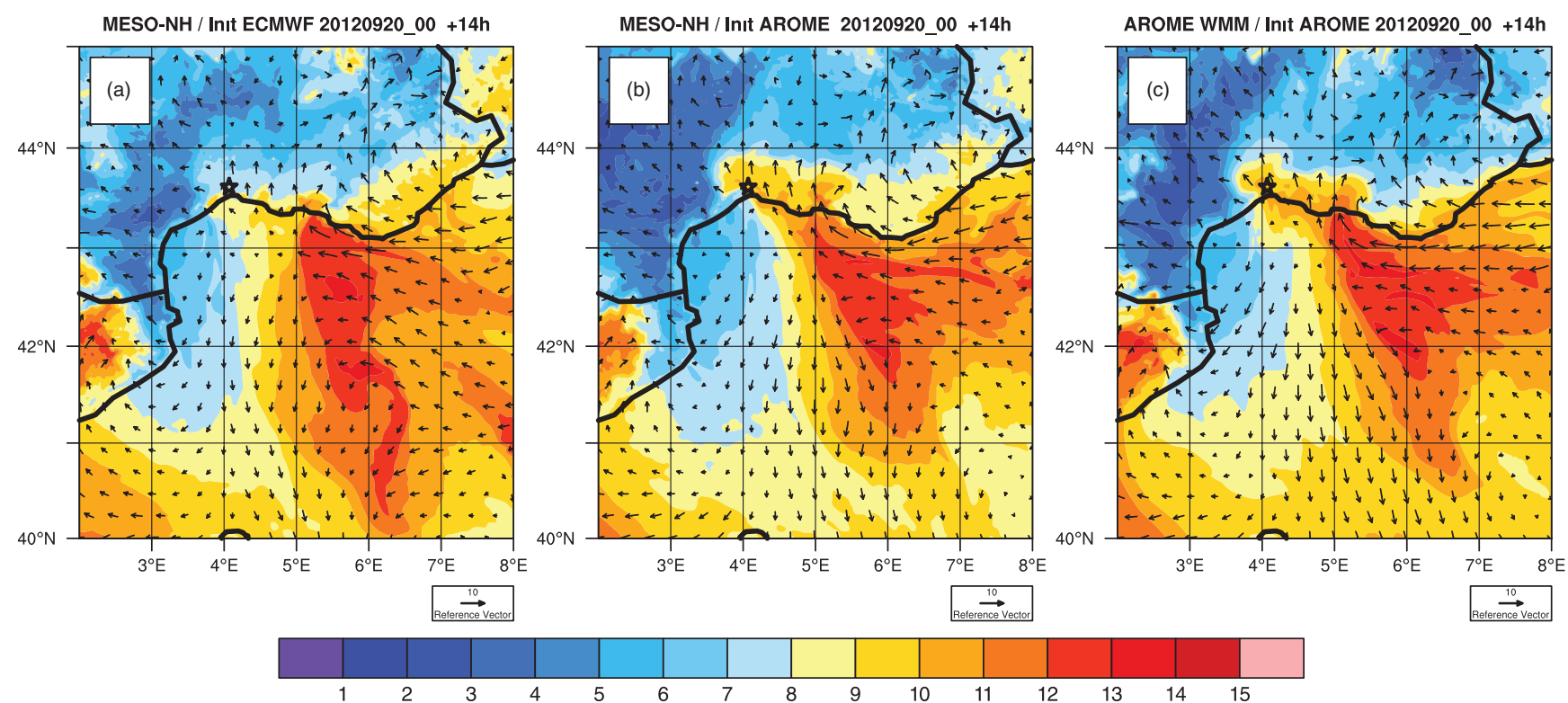

Figure 19. Impact of the initial conditions on Meso-NH forecasts: $2 \mathrm{~m}$ water vapour mixing ratio forecast $\left(\mathrm{g} \mathrm{kg}^{-1}\right)$ for 20 September 2012 at $1400 \mathrm{UTC}$ obtained with (a) Meso-NH initialized with the 0000 UTC ECMWF analysis, (b) Meso-NH initialized with the 0000 UTC AROME-WMED analysis, and (c) AROME-WMED initialized with the 0000 UTC AROME-WMED analysis.

marine flow in combination with the synoptic easterly flow also visible in the forecast. For the sake of completeness, it is to be pointed out that switching off the radiation scheme results into the removal of the diurnal cycle, which, besides altering the thermally generated mesoscale circulation, also leads to an inhibition of evaporation from the surface, with a consequent impact on the $2 \mathrm{~m}$ water vapour mixing ratio difference between the reference forecast and the no-radiation forecast.

The goal of the second sensitivity experiment was to investigate the source of model result discrepancies between Meso-NH and AROME-WMED observed for the case-study on $19 / 20$ September 2012 (i.e. the case which exhibits the largest discrepancies between the two models) and get an assessment of the sensitivity to the initial conditions. For this purpose Meso-NH was rerun using as initial conditions the 0000 UTC AROME-WMED analysis instead of the ECMWF 0000 UTC analysis. Figure 19 compares the surface water vapour mixing ratio forecasted by Meso-NH at 1400 UTC 20 September 2012 with the one forecasted by AROME-WMED. The figure clearly reveals that the AROME-based Meso-NH forecast is much closer to the AROME forecast than the ECMWF-based Meso-NH forecast, consequently demonstrating that the lack of moisture in Candillargues on 19/20 September 2012 obtained with the Meso-NH reference forecast can be primarily explained by the differences in the initialization. This result clearly highlights the benefit of a high-resolution analysis.

\section{Summary}

This article reports state-of-the-art lidar measurements documenting the occurrence of low-level wind reversals associated with transition events from Mistral/Tramontane to southerly marine flow taking place in southern France. Measurements were performed by the ground-based Raman lidar system BASIL and the airborne DIAL system LEANDRE 2 focusing on three selected case-studies (19/20 September 2012, 10-12 October 2012, 13-15 October 2012) during HyMeX SOP1. These two active-laser remote sensors provide accurate and high spaceand time-resolution measurements of the vertical profiles of the water vapour mixing ratio and aerosol backscatter (not shown for LEANDRE 2). The high spatial and temporal resolution of these systems allow us to get a unique insight into the time evolution of the three-dimensional water vapour and aerosol fields during the low-level wind reversal events and document the large time and space variability of the water vapour and aerosol fields. A large variability of the water vapour within the boundary layer is found to take place from/to typical values in the range $4-8 \mathrm{~g} \mathrm{~kg}^{-1}$ during the northerly Mistral/Tramontane flows to/from values in the range $8-15 \mathrm{~g} \mathrm{~kg}^{-1}$ during the southerly marine flows. Measurements allow identifying the quite sharp separation between these two flows. The increase/decrease in water vapour mixing ratio within the boundary layer is abrupt and marked in the transition periods, with values increasing/decreasing by a factor of $2-4$ in a matter of $1 \mathrm{~h}$. This is particularly true during the combined occurrence of a sea-breeze event with a southeasterly flow, leading to a significant penetration inland and intensification of the low-level southerly flow, as for the first case-study reported in the article (19/20 September 2012). Above the boundary-layer top the water vapour variability associated with these transition events is limited as a result of the fact that the wind reversal is taking place only within the boundary layer and not extending to the free troposphere.

Significant changes in particle backscatter are also found to accompany these transition events, with the arrival of humid air advected by the southerly marine flow, which is typically characterized by a larger aerosol loading, likely of maritime origin, which replaces the drier air advected by the northerly Mistral/Tramontane flows, most likely including continental aerosols. As a result of this air-mass change, particle backscatter is found to typically increase by approximately $30-50 \%$ from the pre-arrival values. The advection of aerosol-laden warm and humid air is often accompanied by the formation of boundarylayer clouds topping the humid layer.

The transitions from Mistral/Tramontane to southerly marine flow are also satisfactorily well captured by the two mesoscale models considered in this article, namely AROME-WMED and Meso-NH, these two models properly reproducing the water vapour field both in timing and amplitude. In one specific case (19/20 September 2012) Meso-NH is found to underestimate the amount of humidity in the boundary layer associated with the southerly marine flow. Both models tend to slightly underestimate the vertical extent of the humid layer within the boundary layer and ultimately underestimate the boundary-layer height, this being however a more general feature observed not only during the considered transition events. These two mesoscale models are also found to properly reproduce the dynamical structures associated with the observed stratospheric intrusion episodes, but only partially simulate the deep penetration into the lower troposphere of the dry intruding layer. 
The mean absolute bias between the two mesoscale models and BASIL is found to not exceed $2 \mathrm{~g} \mathrm{~kg}^{-1}$, with the bias of Meso-NH vs. BASIL being larger (by $\sim 0.5 \mathrm{~g} \mathrm{~kg}^{-1}$ ) than the bias of AROMEWMED vs. BASIL, while the relative bias has values in the range 5-20\% (except for the case-study on 19/20 September 2012 in the proximity and above the boundary-layer top because of the presence of a very dry and thin region that model resolution does not allow to capture well). The better scores for AROME-WMED are likely related to the different initial conditions considered for both models (a specific sensitivity experiment has been carried out on that) rather than to the model physical parametrizations, as these latter are similar.

The results of this article demonstrate the capability of lidar systems to capture the fast temporal evolution of the water vapour field in the lower troposphere associated with the lowlevel wind reversals, thus permitting an accurate identification in space and time of the transition events from Mistral/Tramontane to southerly marine flow. This information is of paramount importance for the verification of NWP models, as in fact the appropriate assessment of the capability of these models to accurately capture these transitions and the associated water vapour variability is crucial to properly forecast the occurrence of heavy precipitation events.

As a possible future continuation and evolution of this specific research effort, we foresee the possibility to further refine the study with the consideration of atmospheric temperature measurements performed by BASIL to reveal possible signatures of these flow transitions also in the measurements of the temperature field. We also foresee the possibility to extend this kind of observation/modelling comparison to different meteorological scenarios, with special attention to those associated with heavy precipitation events in the area of study.

\section{Acknowledgements}

This work is a contribution to the HyMeX programme supported by MISTRALS and ANR IODA-MED Grant ANR-11-BS56-0005. This research effort was supported by the European Commission under the European Facility for Airborne Research programme of the seventh Framework Programme (Project WaLiTemp). Airborne data was obtained using the ATR42 Environment Research Aircraft operated and managed by Service des Avions Français Instrumentés pour la Recherche en Environnement (SAFIRE, www.safire.fr), which is a joint entity of CNRS, MétéoFrance and CNES. The SAFIRE staff are thanked for their support during the SOP1. The authors are grateful to D. Bruneau, P. Genau, C. Merlet, T. Deleporte, S. Bastin, C. Kocha, C. Lavaysse and R. Meynadier (LATMOS) as well as F. Blouzon and A. Abchiche (DT/INSU) for operating the LEANDRE 2 system aboard the ATR42 during HyMeX-SOP1. We would like to also thank the CNRM (Météo-France) for operating the UHF wind profiler in Candillargues and SEDOO (Observatoire MidiPyrénées) for supporting its database management. Finally, the authors would like to thank the three anonymous referees for their thorough reviews and comments that helped improve the article significantly.

\section{References}

Ackerman SA, Knox JA. 2003. Meteorology: Understanding the Atmosphere Jones and Bartlett Learning: Burlington, MA.

Banta RM. 1995. Sea breezes shallow and deep on the California coast. Mon Weather Rev. 123: 3614-3622.

Bastin S, Drobinski P. 2005. Temperature and wind velocity oscillations along a gentle slope during sea-breeze events. Boundary-Layer Meteorol. 114: 573-594.

Bastin S, Champollion C, Bock O, Drobinski P, Masson F. 2005a. On the use of GPS tomography to investigate water vapor variability during a Mistral/sea breeze event in southeastern France. Geophys. Res. Lett. 32: L05808, doi: 10.1029/2004GL021907.

Bastin S, Drobinski P, Dabas AM, Delville P, Reitebuch O, Werner C. 2005b. Impact of the Rhône and Durance Valleys on sea-breeze circulation in the Marseille area. Atmos. Res. 74: 303-328.
Bastin S, Drobinski P, Guénard V, Caccia JL, Campistron B, Dabas AM, Delville P, Reitebuch O, Werner C. 2006. On the interaction between the sea breeze and a summer Mistral event at the exit of the Rhône valley. Mon. Weather Rev. 134: 1647-1668.

Bhawar R, Di Girolamo P, Summa D, Flamant C, Althausen D, Behrendt A, Kiemle C, Bosser P, Cacciani M, Champollion C, Di Iorio T, Engelmann R, Herold C, Müller D, Pal S, Wirth M, Wulfmeyer V. 2011. The water vapour intercomparison effort in the framework of the Convective and Orographically-induced Precipitation Study: Airborne-to-ground-based and airborne-to-airborne lidar systems. Q. J. R. Meteorol. Soc. 137:325-348, doi: 10.1002/qj.697.

Bresson E, Ducrocq V, Nuissier O, Ricard D, de Saint-Aubin C. 2012. Idealized numerical study of southern France heavy precipitating events: Identification of favouring ingredients. Q. J. R. Meteorol. Soc. 138: $1751-1763$.

Bruneau D, Quaglia P, Flamant C, Meissonnier M, Pelon J. 2001a. Airborne lidar LEANDRE II for water-vapor profiling in the troposphere. I: System description. Appl. Opt. 40: 3450-3461.

Bruneau D, Quaglia P, Flamant C, Pelon J. 2001b. Airborne lidar LEANDRE II for water-vapor profiling in the troposphere. II: First results. Appl. Opt. 40: $3462-3475$.

Campins J, Jansa A, Benech B, Koffi E, Bessemoulin P. 1995. PYREX observation and model diagnosis of the Tramontane wind. Meteorol. Atmos. Phys. 56: 209-228.

Caniaux G, Redelsperger JL, Lafore JP. 1994. A numerical study of the stratiform region of a fast-moving squall line. Part I. General description, and water and heat budgets. J. Atmos. Sci. 51: 2046-2074.

Cuxart J, Bougeault P, Redelsperger JL. 2000. A turbulence scheme allowing for mesoscale and large-eddy simulations. Q. J. R. Meteorol. Soc. 126: 1-30.

Delbarre H, Augustin P, Saïd F, Campistron B, Bénech B, Lohou F, Puygrenier V, Moppert C, Cousin F, Fréville P, Fréjafon E. 2005. Ground-based remote sensing observation of the complex behaviour of theMarseille boundary layer during ESCOMPTE. Atmos. Res. 74: 403-433.

Di Girolamo P, Ambrico PF, Amodeo A, Boselli A, Pappalardo G, Spinelli N. 1999. Aerosol observations by lidar in the nocturnal boundary layer. Appl. Opt. 38: 4585-4595, doi: 10.1364/AO.38.004585.

Di Girolamo P, Marchese R, Whiteman DN, Demoz BB. 2004. Rotational Raman lidar measurements of atmospheric temperature in the UV. Geophys. Res. Lett. 31: L01106, doi: 10.1029/2003GL018342.

Di Girolamo P, Behrendt A, Wulfmeyer V. 2006. Spaceborne profiling of atmospheric temperature and particle extinction with pure rotational Raman lidar and of relative humidity in combination with differential absorption lidar: performance simulations. Appl. Opt. 45: 2474-2494, doi: 10.1364/AO.45.002474.

Di Girolamo P, Summa D, Ferretti R. 2009a. Multiparameter Raman lidar measurements for the characterization of a dry stratospheric intrusion event. J. Atmos. Oceanic Technol. 26: 1742-1762, doi: 10.1175/2009JTECHA1253.1.

Di Girolamo P, Summa D, Lin RF, Maestri T, Rizzi R, Masiello G. 2009b. UV Raman lidar measurements of relative humidity for the characterization of cirrus cloud microphysical properties. Atmos. Chem. Phys. 9: 8799-8811, doi: 10.5194/acp-9-8799-2009.

Di Girolamo P, Summa D, Bhawar R, Di Iorio T, Cacciani M, Veselovskii I Dubovik O, Kolgotin A. 2012a. Raman lidar observations of a Saharan dust outbreak event: Characterization of the dust optical properties and determination of particle size and microphysical parameters. Atmos. Environ. 50: 66-78, doi: 10.1016/j.atmosenv.2011.12.061.

Di Girolamo P, Summa D, Cacciani M, Norton EG, Peters G, Dufournet Y 2012b. Lidar and radar measurements of the melting layer: observations of dark and bright band phenomena. Atmos. Chem. Phys. 12: 4143-4157, doi: 10.5194/acp-12-4143-2012.

Draxler RR, Rolph GD. 2003. HYSPLIT (HYbrid Single-Particle Lagrangian Integrated Trajectory) Model. NOAA Air Resources Laboratory. http://www .arl.noaa.gov/ready/hysplit4.html) (accessed 5 June 2014)

Drobinski P, Flamant C, Dusek J, Flamant PH, Pelon J. 2001. Observational evidence and modeling of an internal hydraulic jump at the atmospheric boundary layer top during a Tramontane event. Boundary-Layer Meteorol. 98: 497-515.

Drobinski P, Bastin S, Guénard V, Caccia JL, Dabas AM, Delville P, Protat A, Reitebuch O, Werner C. 2005. Summer Mistral at the exit of the Rhône valley. Q. J. R. Meteorol. Soc. 131: 353-375.

Drobinski P, Ducrocq V, Alper P, Anagnostou E, Béranger K, Borga M, Braud I, Chanzy A, Davolio S, Delrieu G, Estournel C, Filali Boubrahmi N, Font J, Grubisic V, Gualdi S, Ivancan-Picek B, Kottmeier C, Kotroni V, Lagouvardos K, Lionello P, Llasat MC, Ludwig W, Lutoff C, Mariotti A, Richard E, Romero R, Rotunno R, Roussot O, Ruin I, Santaner VH, Somot S, Taupier-Letage I, Tintore J, Uijlenhoet R, Wernli H. 2014. HyMeX, a 10-year multidisciplinary program on the Mediterranean water cycle. Bull. Am. Meteorol. Soc. 95: 1063-1082, doi: 10.1175/BAMS-D-12-00242.1.

Ducrocq V, Braud I, Davolio S, Ferretti R, Flamant C, Jansà A, Kalthoff N, Richard E, Taupier-Letage I, Ayral P-A, Belamari S, Berne A, Borga M, Boudevillain B, Bock O, Boichard J-L, Bouin M-N, Bousquet O, Bouvier C, Chiggiato J, Cimini D, Corsmeier U, Coppola L, Cocquerez P, Defer E, Delanoë J, Di Girolamo P, Doerenbecher A, Drobinski P, Dufournet Y, Fourrié N, Gourley JJ, Labatut L, Lambert D, Le Coz J, Marzano FS, Molinié G, Montani A, Nord G, Nuret M, Ramage K, Rison B, Roussot O, Saïd F, 
Schwarzenboeck A, Testor P, Van-Baelen J, Vincendon B, Aran M, Tamayo J. 2014. HyMeX-SOP1, the field campaign dedicated to heavy precipitation and flash-flooding in northwestern Mediterranean. Bull. Am. Meteorol. Soc. 95: 1083-1100, doi: 10.1175/BAMS-D-12-00244.1.

Estournel C, Durrieu de Madron X, Marsaleix P, Auclair F, Julliand C, Vehil R. 2003. Observation and modeling of the winter coastal oceanic circulation in the Gulf of Lion under wind conditions influenced by the continental orography (FETCH experiment). J. Geophys. Res. 108: 8059, doi: 10.1029/2001JC000825.

Flamant C. 2003. Alpine lee cyclogenesis influence on air-sea heat exchanges and marine atmospheric boundary layer thermodynamics over the western Mediterranean during a Tramontane/Mistral event. J. Geophys. Res. 108: 8057, doi: 10.1029/2001JC001040

Fourrié N, Bresson É, Nuret M, Jany C, Brousseau P, Doerenbecher A, Kreitz M, Nuissier O, Sevault E, Bénichou H, Amodei M, Pouponneau F. 2015. AROME-WMED, a real-time mesoscale model designed for the HyMeX Special Observation Periods. Geosci. Model Dev. Discuss. 8: 1801-1856, doi: 10.5194/gmdd-8-1801-2015.

Georgelin M, Richard E. 1996. Numerical simulation of flow diversion around the Pyrenees: A tramontana case study. Mon. Weather Rev. 124: $687-700$.

Griaznov V, Veselovskii I, Di Girolamo P, Korenskii M, Summa D. 2007. Spatial distribution of doubly scattered polarized laser radiation in the focal plane of a lidar receiver. Appl. Opt. 46: 6821-6830.

Guénard V, Drobinski P, Caccia JL, Campistron B, Bénech B. 2005. An observational study of the mesoscale Mistral dynamics. Boundary-Layer Meteorol. 115: 263-288.

Guénard V, Drobinski P, Caccia JL, Tedeschi G, Currier P. 2006. Dynamics of the MAP IOP-15 severe Mistral event: observations and high-resolution numerical simulations. Q. J. R. Meteorol. Soc. 132: 757-778.

Jansá A. 1987. Distribution of the Mistral: A satellite observation. Meteorol. Atmos. Phys. 36: 201-214, doi: 10.1007/BF01045149.

Kalthoff N, Kottmeier C, Thurauf J, Corsmeier U, Saïd F, Frejafon E, Perros PE. 2005. Mesoscale circulation systems and ozone concentrations during ESCOMPTE: A case study from IOP2b. Atmos. Res. 74: 355-380.

Lafore JP, Stein J, Asencio N, Bougeault P, Ducrocq V, Duron J, Fischer C, Héreil P, Mascart P, Masson V, Pinty JP, Redelsperger JL, Richard E, VilàGuerau de Arellano J. 1998. The Méso-NH atmospheric simulation system. Part I: Adiabatic formulation and control simulations. Ann. Geophys. 16: 90-109.

Lebeaupin-Brossier C, Arsouze T, Béranger K, Bouin MN, Bresson E, Ducrocq V, Giordani H, Nuret M, Rainaud R, Taupier-Letage I. 2014. Ocean mixed layer responses to intense meteorological events during HyMeXSOP1 from a high-resolution ocean circulation. Ocean Modelling 84: 84-103.

Lemonsu A, Bastin S, Masson V, Drobinski P. 2006. Vertical structure of the urban boundary layer over Marseille under sea breeze conditions. Boundary-Layer Meteorol. 118: 477-501.
Masson V, Le Moigne P, Martin E, Faroux S, Alias A, Alkama R, Belamari S, Barbu A, Boone A, Bouyssel F, Brousseau P, Brun E, Calvet JC, Carrer D, Decharme B, Delire C, Donier S, Essaouini K, Gibelin A-L, Giordani H, Habets F, Jidane M, Kerdraon G, Kourzeneva E, Lafaysse M, Lafont S, Lebeaupin Brossier C, Lemonsu A, Mahfouf J-F, Marguinaud P, Mokhtari M, Morin S, Pigeon G, Salgado R, Seity Y, Taillefer F, Tanguy G, Tulet P, Vincendon B, Vionnet V, Voldoire A. 2013. The SURFEXv7.2 land and ocean surface platform for coupled or offline simulation of Earth surface variables and fluxes. Geosci. Model Dev. 6: 929-960, doi: 10.5194/gmd-6-929-2013.

Noilhan J, Planton S. 1989. A simple parameterization of land surface processes for meteorological models. Mon. Weather Rev. 117: 536-549.

Pergaud J, Masson V, Malardel S, Couvreux F. 2009. A parameterization of dry thermals and shallow cumuli for mesoscale numerical weather prediction. Boundary-Layer Meteorol. 132: 83-106.

Pinty J-P, Jabouille P. 1998. A mixed-phase cloud parameterization for use in mesoscale non-hydrostatic model: simulations of a squall line and of orographic precipitations. In Proceedings of Conference on Cloud Physics, 17-21 August, Everett, WA: 217-220. American Meteorological Society: Boston.

Rainaud R, Lebeaupin Brossier C, Ducrocq V, Giordani H, Nuret M, Fourrié N, Bouin M-N, Taupier-Letage I, Legain D. 2015. Characterization of air-sea exchanges over the Western Mediterranean Sea during HyMeX SOP1 using the AROME-WMED model. Q. J. R. Meteorol. Soc. doi: 10.1002/qj.2480.

Ricard D, Ducrocq V, Auger L. 2012. A climatology of the mesoscale environment associated with heavily precipitating events over a northwestern Mediterranean area. J. Appl. Meteorol. Clim. 51: 468-488, doi: 10.1175/JAMC-D-11-017.1.

Russell A, Vaughan G, Norton EG, Ricketts HMA, Morcrette CJ, Hewison TJ, Browning KA, Blyth AM. 2009. Convection forced by a descending dry layer and low-level moist convergence. Tellus A 61: 250-263, doi: 10.1111/j.1600-0870.2008.00382.x.

Russell A, Vaughan G, Norton EG. 2012. Large-scale potential vorticity anomalies and deep convection. Q. J. R. Meteorol. Soc. 138: 1627-1639, doi: 10.1002/qj.1875.

Saïd F, Brut A, Campistron B, Cousin F. 2007. Investigation of the atmospheric boundary layer dynamics during the ESCOMPTE campaign. Ann. Geophys. 25: 597-622, doi: 1432-0576/angeo/2007-25-597.

Saîd F, Campistron B, Delbarre H, Canut G, Doerenbecher A, Durand P, Fourrié N, Lambert D,, Legain D. 2016. Offshore winds obtained from a network of wind profiler radars during HyMeX. Q. J. R. Meteorol. Soc. doi: 10.1002/qj.2749.

Schott F, Visbeck M, Send U, Fischer J, Stramma L, Desaubies Y. 1996. Observations of deep convection in the Gulf of Lions, northern Mediterranean, during the winter of 1991/1992. J. Phys. Oceanogr. 26: 505-524.

Seity Y, Brousseau P, Malardel S, Hello G, Bénard P, Bouttier F, Lac C, Masson V. 2011. The AROME-France convective-scale operational model. Mon. Weather. Rev. 139: 976-991, doi: 10.1175/2010MWR3425.1. 